\title{
Best Management Practices and Nutrient Reduction: An Integrated Economic-Hydrologic Model of the Western Lake Erie Basin
}

\author{
Hongxing Liu, Wendong Zhang, Elena Irwin, Jeffery Kast, Noel Aloysius, Jay Martin, \\ Margaret Kalcic
}

\author{
Working Paper 20-WP 601 \\ April 2020
}

\author{
Center for Agricultural and Rural Development \\ lowa State University \\ Ames, lowa 50011-1070 \\ www.card.iastate.edu
}

Hongxing Liu is Assistant Professor, Department of Economics, Lafayette College, Easton, PA 18042. Email: liuho@lafayette.edu.

Wendong Zhang is Associate Professor, Department of Economics, lowa State University, Ames, IA 50010. E-mail: wdzhang@iastate.edu

Elena Irwin is Professor, Department of Agricultural, Environmental, and Developmental Economics, Ohio State University, Columbus, OH 43210. E-mail: irwin.78@osu.edu.

Jeffery Kast is Ph.D. Student, Department of Food, Agricultural, and Biological Engineering, Ohio State University, Columbus, OH 43210. E-mail: kast.14@osu.edu.

Noel Aloysius is Assistant Professor, Department of Bioengineering, University of Missouri, Columbia, MO 65201. E-mail: aloysiusn@missouri.edu.

Jay Martin is Professor, Department of Food, Agricultural, and Biological Engineering Ohio State University, Columbus, OH 43210. E-mail: martin.1130@osu.edu.

Margaret Kalcic is Assistant Professor, Department of Food, Agricultural, and Biological Engineering, Ohio State University, Columbus, OH 43210. E-mail: kalcic.4@osu.edu.

This publication is available online on the CARD website: www.card.iastate.edu. Permission is granted to reproduce this information with appropriate attribution to the author and the Center for Agricultural and Rural Development, lowa State University, Ames, lowa 50011-1070.

For questions or comments about the contents of this paper, please contact Wendong Zhang, wdzhang@iastate.edu.

lowa State University does not discriminate on the basis of race, color, age, ethnicity, religion, national origin, pregnancy, sexual orientation, gender identity, genetic information, sex, marital status, disability, or status as a U.S.

veteran. Inquiries regarding non-discrimination policies may be directed to Office of Equal Opportunity, 3410

Beardshear Hall, 515 Morrill Road, Ames, lowa 50011, Tel. (515) 294-7612, Hotline: (515) 294-1222, email

eooffice@iastate.edu. 


\section{Best Management Practices and Nutrient Reduction:}

\section{An Integrated Economic-Hydrologic Model of the Western Lake Erie Basin}

Hongxing Liu ${ }^{1}$, Wendong Zhang ${ }^{2}$, Elena Irwin ${ }^{3}$, Jeffrey Kast ${ }^{4}$, Noel Aloysius ${ }^{5}$, Jay Martin ${ }^{6}$, and Margaret Kalcic ${ }^{7}$

${ }^{1}$ Assistant Professor, Department of Economics, Lafayette College. 206 William Simon Center, 30 S College Dr., Easton, PA 18042, United States. Email address: liuho@lafayette.edu

${ }^{2}$ Assistant Professor, Department of Economics and Center for Agricultural and Rural Development, Iowa State University. 478C Heady Hall, 518 Farm House Lane, Ames, IA 50011, United States. Email address: wdzhang@iastate.edu

${ }^{3}$ Professor, Agricultural, Environmental, and Development Economics Department and Sustainability Institute, Ohio State University. 316 Ag Admin Building, 2120 Fyffe Road Columbus, OH 43210, United States. Email address: irwin.78@,osu.edu

${ }^{4}$ Ph.D. student, Department of Food, Agricultural and Biological Engineering, Ohio State University. Agricultural Engineering. 590 Woody Hayes Drive, Columbus, OH 43210, United States. Email address: kast.14@osu.edu

${ }^{5}$ Assistant Professor, Department of Bioengineering and School of Natural Resources, University of Missouri. 254 Ag Engineering Building, 1406 Rollins St, Columbia, MO 65201, United States. Email address: aloysiusn@missouri.edu

${ }^{6}$ Professor, Department of Food, Agricultural and Biological Engineering and Sustainability Institute, Ohio State University. 230C Agricultural Engineering. 590 Woody Hayes Drive, Columbus, OH 43210, United States. Email address: martin.1130@osu.edu

${ }^{7}$ Assistant Professor, Department of Food, Agricultural and Biological Engineering, Ohio State University. 228C Agricultural Engineering. 590 Woody Hayes Drive, Columbus, OH, 43210, United States. Email address: kalcic.4@,osu.edu

Forthcoming at Land Economics 


\begin{abstract}
We develop the first spatially integrated economic-hydrological model of the western Lake Erie basin explicitly linking economic models of farmers' field-level Best Management Practice (BMP) adoption choices with the Soil and Water Assessment Tool (SWAT) model to evaluate nutrient management policy cost-effectiveness. We quantify tradeoffs among phosphorus reduction policies and find that a hybrid policy coupling a fertilizer tax with cost-share payments for subsurface placement is the most cost-effective, and when implemented with a $200 \%$ tax can achieve the stated policy goal of $40 \%$ reduction in nutrient loadings. We also find economic adoption models alone can overstate the potential for BMPs to reduce nutrient loadings by ignoring biophysical complexities.
\end{abstract}

Key Words: Integrated assessment model; agricultural land watershed model; water quality; cost-share; conservation practice; nutrient management

JEL Codes: H23, Q51, Q52, Q53 


\section{Introduction}

Agricultural nutrient runoff, especially phosphorus (P), from the Maumee River watershed in the western Lake Erie basin has led to frequent and severe water quality crises, including harmful algal blooms (HABs) and hypoxia in Lake Erie and the 2014 Toledo water crisis (Lake Erie LaMP 2011; Scavia et al. 2014; Stumpf et al. 2012). To address these growing concerns, the United States and Canada adopted a revised version of the Great Lakes Water Quality Agreement (GLWQA) in 2012, which aims to reduce total phosphorus (TP) and dissolved reactive phosphorus (DRP) entering affected areas of Lake Erie by $40 \%$ relative to the 2008 loading levels (Binational.net 2012). At the national level, spending on federally funded conservation programs is projected to be over $\$ 5.5$ billion annually, or about $\$ 15$ per acre per year, during the five-year life of the 2014 Farm Bill. At the state level, Ohio's Senate Bill 1, signed in early 2015 , requires nutrient management plans for all producers, prohibits manure or fertilizer application on frozen grounds and 24 hours before a forecasted storm, and encourages injecting or incorporating fertilizer or manure application into the ground. Despite these efforts, the 2015 Lake Erie HAB was even larger and more severe than the HAB recorded in 2011 (Stumpf et al. 2016) and the issue continues to be at the forefront of environmental and agricultural policy issues for the Great Lakes region.

A key feature of federal and state programs is that they are often voluntary, with producers opting to participate receiving a cost-share payment covering part or all of the best management effort. Despite their prevalence, there is a significant lack of empirical evidence of the cost-effectiveness of these cost-share programs in terms of their downstream impacts (Garnache et al. 2016). While these incentives have effectively encouraged farmer adoption of best management practices (BMPs), it is unknown if they are economically cost-efficient, which 
would greatly depend on the extent to which these land management changes are successful in reducing nutrient loadings and improving water quality benefits.

This article fills a critical policy evaluation gap by developing a spatially integrated economic-hydrological model that explicitly links individual land management decisions by heterogeneous farmers on heterogeneous fields with a hydrological process model to evaluate the cost-effectiveness of various nutrient management policies. Specifically, we link farmer-surveybased economic models of BMP adoption with the widely used hydrological-process-based Soil and Water Assessment Tool (SWAT) model. The economic models include an ordered logit model that explains how BMP adoption costs and cost-share payment subsidies drive changes in adoption behavior, and a fertilizer demand model to analyze and predict farmers' fertilizer application rate decisions under fertilizer taxes. Our SWAT model incorporates BMP decisions, geophysical data such as soil type, and climate information as inputs to assess the effectiveness of different policy scenarios in reducing nutrient runoff at the watershed scale. With this integrated economic-hydrological model, we are able not only to quantify the changes in conservation practice adoption on an individual field scale in response to policy incentives, but also to simulate the resulting impacts from the watershed on water quality changes, specifically TP and DRP loadings.

We apply this model to the biggest Great Lakes watershed — the Maumee River watershed - to quantify the tradeoff between P reduction and policy costs for a range of alternative policies and to investigate which of these policies has the potential to reach the policy target of a $40 \%$ reduction in phosphorus loadings to Lake Erie. The Maumee watershed is the largest source of $\mathrm{P}$ loadings into Lake Erie and the primary driver of the extent of Lake Erie HABs (Maccoux et al. 2016, Scavia et al. 2014). Using a 2014 survey of 2,324 respondents of 
farmers from this watershed that provides extensive information on farmers' BMP choices, field characteristics, and demographics (Burnett et al. 2015), we examine three salient in-field conservation practices - subsurface fertilizer placement (via banding or in-furrow with seed), post-fall-harvest cover crops, and $\mathrm{P}$ fertilizer application rate reduction —all of which have been shown to be critical and promising in reducing nutrient runoff (Wilson et al. 2019; Gildow et al. 2016; Mahler 2001; Scavia et al. 2014). Our integrated model allows us to assess the costeffectiveness of cost-share payments that are currently in place under a range of possible payment amounts as well as three hypothetical policies: $(a)$ a fertilizer tax, which ranges in magnitude from $0 \%$ to $400 \%$ of the producer-specific P fertilizer price; $(b)$ a spatially-targeted zonal policy that only offers cost-share payments to farmers in the nutrient runoff "hotspot" counties; and, $(c)$ a revenue-neutral hybrid policy that administers a fertilizer tax and then redistributes those revenues to producers in the form of cost-share payments for adoption of subsurface placement or cover crops.

The main results show that either a substantial increase in fertilizer costs through a tax, or a hybrid approach that combines a somewhat lower fertilizer tax with cost-share incentives for subsurface placement, can meet this policy target. Specifically, we find that a $400 \%$ fertilizer tax on the producer-specific $\mathrm{P}$ fertilizer price can generate a $39.5 \%$ reduction in TP, while a $200 \%$ fertilizer tax that is recycled for cost-share payments for subsurface placement can lead to $40.5 \%$ reduction in TP. ${ }^{\mathrm{i}}$ In comparison, a very ambitious cost share program of $\$ 80 /$ acre uniformly offered to all farmers reduces DRP loadings by $13 \%$ and TP loadings by $8 \%$ and imposes $\$ 188$ million in annual policy costs. In comparison, farmers in Ohio received about $\$ 36$ million in cost share payments from the USDA EQIP program in 2018 (USDA NRCS 2018). Based on the 
model scenarios and results considered here, this outlay could at best generate less than $5 \% \mathrm{P}$ loading reduction even if used exclusively for incentivizing subsurface placement.

Another key result of our study is that subsurface placement of fertilizer is a more effective BMP than cover crops in terms of reducing P loading. More importantly, looking at the cost-share payment programs, despite significantly higher adoption of the targeted BMPs under various policy scenarios, the resulting watershed-scale reduction in P loadings at best account for less than half of the prescribed $40 \%$ nutrient reduction goal. For example, we find that, while the \$80/acre uniform cost-share payment for farmers to adopt subsurface placement would increase the total cropland acres in the watershed from $46 \%$ to $65 \%$, the corresponding percent reduction in nutrient loadings is much less $-13 \%$ and $8 \%$ in DRP and TP loadings, respectively. Even with the spatially targeted payment that targets the runoff "hotspot" counties, which is more costeffective than the uniform cost-share payments, we observe a similar reduction at a slightly lower total cost. The lack of responsiveness in water quality could be a result of the hydrologic and biophysical complexities, including legacy $\mathrm{P}$ attached to soils and hydrological routing within the watershed. Thus, more innovative policies that provide alternative approaches to reduce nutrient runoff are needed.

By integrating both the economic and biophysical systems in a spatially explicit framework that also accounts for individual decision making, this work makes novel contributions and extends the literature in multiple ways. A substantial literature examines farmers' adoption of BMPs and the role of monetary incentives (e.g., Blackstock et al. 2010), adoption costs (e.g., Sheriff 2005; Kurkalova et al. 2006), and farmers' socio-economic and socio-psychological characteristics (e.g., Norris and Batie 1987; Zhang et al. 2016; Burnett et al. 2015; Wu et al. 2004). However, these studies focus on individual decision making and most do 
not explicitly consider downstream water quality impacts and, thus, are unable to fully evaluate policy effectiveness. On the other hand, a growing number of hydrological process-based models have been developed for Lake Erie and other areas of the Great Lakes region; however, these models omit behavioral or economic considerations and therefore must impose assumptions about BMP adoption (e.g., assuming full or random adoption, see Scavia et al. 2017 and Bosch et al. 2014). We demonstrate the value and necessity of integrated assessment models to identify realistic policy impacts of nutrient management policies and quantify the social cost of water quality. We show that ignoring biophysical complexity, as is typical of most economics models, or imposing unrealistic simplified adoption behavior, as is typical of most hydrological models, could lead to significant overestimation of the cost-effectiveness of agri-environmental policies in reducing nutrient runoff.

In addition, by accounting for heterogeneity in farmer decision making in quantifying the effectiveness of alternative economic-based incentives and policies, our article makes novel contributions to integrated assessment modeling for policy analysis. Previous nutrient policy evaluation studies may consider both economic costs and environmental outcomes, but are either reduced-form in nature (e.g., Sohngen et al. 2015) or assume simplified economic adoption outcomes to focus on geophysical or hydrological processes in the watershed (e.g., Laukkanen and Nauges 2014; Rabotyagov et al. 2014). A limitation is that, by omitting an explicit farmers' BMP choice model, they are unable to assess the potential impacts of alternative policy interventions or account for the potential differences in choice behaviors across heterogeneous farmers. By coupling realistic representation of farmer BMP adoption behavior with a hydrological process model and translates individual behavior changes into watershed-scale water quality outcomes, we are able to account for heterogeneous responses to hypothetical 
policy alternatives. To the best of our knowledge, this is the first integrated model of the Lake Erie basin that captures these essential features and allows for more realistic policy scenarios.

Finally, by demonstrating the need and importance of broadening the nutrient management policy toolboxes to move beyond existing cost-share programs, the results are important for informing water quality policy. None of the single BMP cost-share payment programs that we analyzed can achieve the $40 \%$ nutrient reduction target even with spatial targeting. Instead, we find that a hybrid policy, in which a tax is used to generate the revenues to incentivize additional BMP adoption policy, is far more effective than expanding the existing cost-share programs - not just because it is revenue neutral, but also because it applies both a carrot (cost share payments) and a stick (higher P fertilizer costs) to incentivize farmers.

\section{Study Area and Data}

The Maumee River watershed in the western Lake Erie basin is a HUC-6 watershed spanning four million acres across three states (northwestern Ohio, northeastern Indiana, and southern Michigan) and is the largest source of P loadings into Lake Erie (Scavia et al. 2014) (see Figure 1). Previous hydrological research shows that $85 \%$ of $\mathrm{P}$ loadings in this watershed come from agricultural fertilizer and manure application on its 10,000 crop farms and 2,000 livestock farms (Scavia et al. 2017). As a result, agricultural nutrient management practices in this watershed are of significant interest in improving water quality in Lake Erie.

[Insert Figure 1 Here: Map of the Maumee River watershed] 
From February to April 2014, we conducted a representative mail survey of 7,500 farmers in the western Lake Erie basin on their field, farm, and operator characteristics as part of a coupled natural-human systems project (Burnett et al. 2015; Martin et al. 2011; Zhang et al. 2016; Zhang 2015). We also solicited field-specific responses on crop choices, fertilizer application, and other BMPs for the 2013 crop year. The addresses of all farmers in the Maumee River watershed were provided by a private vendor compiled from lists of farmers receiving government payments and from farming magazine subscription rolls. The two-round survey was conducted following Dillman's Tailored Design method (Dillman 2011). The total set of mailings included an announcement letter, a survey packet, a reminder letter, and a replacement packet for non-responders. Respondents received a $\$ 1$ bill in the mailings as an incentive to increase the response rate. The survey was pilot-tested using farmers recruited by local extension professionals several months before the initial mailings.

A total of 3,234 surveys were initially returned, and of these returned surveys 438 were no longer farming and another 32 did not answer the crop management questions. In total, we obtained 2,324 valid survey responses, yielding a response rate of 37\%. A comparison between our data and the Census of Agriculture data for counties in the Maumee River watershed reveals that our sample is skewed toward large farms with high gross sales and farmers earning additional off-farm income. ${ }^{\text {ii }}$ The average farm size is larger than that of the 2012 Census of Agriculture for counties in this watershed; however, larger farms have more potential to impact the water quality in Lake Erie (Zhang et al 2016). A descriptive report on this survey can be found in Burnett et al. (2015). More descriptions on this survey can also be found in Zhang (2015) and Zhang et al. (2016). 
Table 1 shows the summary statistics of the survey, including farmers' BMP adoption, their socio-psychological and demographic characteristics, and farm and field characteristics. In this article, we focus on three conservation practices identified by multiple models as critical and effective in reducing nutrient runoff from the Maumee River watershed. These practices include subsurface fertilizer placement via banding or in-furrow with seed (referred to as subsurface placement), post-fall-harvest cover crops (referred to as cover crops), and commercial fertilizer application rate reduction (referred to as P rate reduction) (Gildow et al. 2016; Kelley and Sweeney 2005; Mahler 2001; Scavia et al. 2014, Scavia et al. 2017). A map of subsurface placement adoption based on the survey is presented in Appendix A.

[Insert Table 1 Here: Variable Description and Summary Statistics]

We construct our dependent variable for subsurface placement and cover crop adoptionwhether the practice has been adopted already and non-adopters' self-expressed attitudes towards future BMP adoption - using two questions from the survey. Attitudes towards future adoption ranges from 0 (will never adopt), to 1 (unlikely to adopt), 2 (likely to adopt), or 3 (will definitely adopt). We combine the already adopted farmers into this variable by assigning the adopted decisions as 4 (have already adopted). We consider farmers responding 3 or 4 as potentially adopting the conservation practice in the next year in the policy simulations, which reduces the risk of overestimating the adoption probability of existing adopters. Table 1 shows that $40 \%$ and $18 \%$ of farmers have already adopted subsurface placement and cover crops, respectively; and, an additional $10 \%$ and $5 \%$ of producers, respectively, report that they will definitely adopt the corresponding practices in the future. Table 1 also shows that on average, farmers in the watershed used 100 pounds of $\mathrm{P}$ fertilizers on a per acre basis, with higher application rates when 
growing corn or applying for more than one year. For farmers who at least applied some $\mathrm{P}$ in 2013, their average application rates are around 113 pounds per acre.

We also include the socio-psychological, socio-economic, and field-level spatial characteristics as explanatory variables (Table 1) as established by previous studies (Huang et al. 2000; Kurkalova et al. 2006; Zhang et al. 2016). The social-psychological characteristics include perceived efficacy, perception of control, risk attitude, and farmer identity, which quantitatively measures farmers' productivity-oriented versus conservationist inclinations (Arbuckle 2013; McGuire et al. 2015). Farmer identity is the difference between conservationist values and productionist values, which could range from -4 (greatest identity as productionist) to 4 (greatest identity as conservationist). For subsurface placement and cover crops, we have a practicespecific perceived efficacy measure that represents the farmers' beliefs in the effectiveness of that particular practice at reducing nutrient loss, ranging from 0 (not at all) to 4 (to a great extent). This psychological factor has been found to be a major driver of farmers' adoption choices of fertilizer timing (Burnett et al. 2015; Zhang et al. 2016), so we expect a higher perceived efficacy of a particular conservation practice in reducing soil loss will lead to higher adoption rate of $\mathrm{P}$ placement or cover crops. Additional socio-psychological measures include the farmer's perceived control over nutrient loss, ranging from 0 (no control) to 6 (complete control), and the farmer's risk attitude measured as the willingness to take risks on a scale from 0 (not willing to take risks) to 10 (very willing to take risks).

For socio-economic characteristics, we include the farmer's age and annual gross income for the 2013 production year (farm_income), which ranges from $1(<\$ 50,000)$, to $2(\$ 50,000-$ $\$ 99,999), 3(\$ 100,000-\$ 249,999), 4(\$ 250,000-\$ 499,999)$, and $5(>\$ 500,000)$. For field-level characteristics, we include the acreage of the field, soil quality (low, medium, or high), slope 
$(0 \%-2 \%, 2 \%-5 \%, 5 \%-10 \%,>10 \%$, not sure $)$, and whether or not the farm is rented. We also calculate a farmer- and practice-specific adoption cost for each practice using farmers' stated expenditures on nutrient inputs, machinery, labor, and farm- or regional-level input prices. Appendices A and B show the data and the methodology of how we constructed this variable.

\section{Spatially Integrated Economic-Hydrological Model}

\subsection{Model Overview and Policy Scenarios}

We link economic models of farmers' BMP adoption decisions with a hydrological model to predict and evaluate the effects of different nutrient management policies on farmers' management decisions and the resulting downstream P loadings into Lake Erie. In particular, we develop three separate field-level farmer decision making models — an ordered logit model of future subsurface placement adoption, an ordered logit model of future cover crops adoption, and a fertilizer demand model for reduction in fertilizer application rates. We use these models to predict changes in the adoption of these practices under each nutrient management policy, and then link them to the SWAT model to simulate the downstream water quality improvements as measured by the reduction in P loadings. The proceeding sections provide more details on each component of this integrated model.

Using this integrated economic-hydrological model, we analyze the cost-share payments for subsurface placement or cover crops. The cost-share payments we examine range from $\$ 1$ to $\$ 80$ per acre, for which the midpoint is close to the USDA-NRCS Environmental Quality Incentives Program payment of $\$ 42.99$ /acre for enhanced nutrient management with deep placement. The alternative nutrient management policy scenarios we examine are a fertilizer tax and a novel tax/cost-share payment combination policy that imposes fertilizer tax for all farmers 
and then uses the tax revenue collected to offer cost-share payments for subsurface placement or cover crops. We hypothesize that alternative nutrient management policies, such as spatially targeted policies or the tax-payment combination policy, could be more cost-effective in achieving nutrient reduction goals.

\subsection{Economic Models of Farmer Decision-making}

\subsubsection{BMP Adoption Model Incorporating Changes in Adoption Costs}

We use an ordered logit model to examine the factors driving the adoption choice of BMPs (subsurface placement and cover crops), and then predict the future likelihood of adoption under different policy incentive programs. We use the ordered logit model following Zhang et al. (2016) because the dependent variable is ordinal and categorical. We estimate the model using the "ologit" command via Stata 15 as follows:

$$
\mathrm{y}_{i k}=\boldsymbol{\alpha}_{j}+\theta \widehat{\mathrm{C}}_{\imath}+\boldsymbol{\beta} \mathbf{I}_{\boldsymbol{i}}+\boldsymbol{\gamma} \mathbf{X}_{\boldsymbol{i}}+\varepsilon, \quad \mathrm{k}=0,1,2,3,4
$$

where the dependent variable $\mathrm{y}_{i k}$ is future adoption decisions of a particular BMP made by farmer $i$, which ranges from 0 (will never adopt), to 1 (unlikely to adopt), 2 (likely to adopt), 3 (will definitely adopt), and 4 (already adopted). The key variable of interest is the predicted farmer-specific adoption costs for this particular BMP $\widehat{\mathrm{C}}_{l}$, which is measured as the additional production costs incurred due to farmer $i^{\prime} s$ adoption of this particular BMP. Appendix C shows in detail how we calculate this adoption cost measure. In a nutshell, we regress the total fieldlevel production costs, measured using the expenditures and inputs reported by the farmer respondent shown in appendix B, on an already-adopted-BMP dummy and its interaction terms with age, field size, and a host of farmer and field characteristics. We use the coefficients for the BMP adoption dummy and its interactions to predict the additional production costs induced by 
the adoption of that particular BMP; and, we then use the predicted values at the individual level in equation (1) as $\widehat{\mathrm{C}_{l}}$. Other explanatory variables in equation (1) include field characteristics $\mathbf{X}_{\boldsymbol{i}}$ (e.g., field size, soil quality, slope, and whether or not the field is rented from others) and farmers' demographic and socioeconomic characteristics $\mathbf{I}_{\boldsymbol{i}}$ (e.g., perceived efficacy of the BMP, mean risk level, identity as a farmer, perceived control over nutrient runoff, age, and gross farm income). We include county-level fixed effects $\boldsymbol{\alpha}_{\boldsymbol{j}}$ and cluster standard errors at the county level to control for unobserved spatial heterogeneity and heteroskedastic errors, which effectively controls for spatial dependence.

Under each scenario with a payment subsidy or a tax-payment combination policy, we predict a farmer's likely future adoption probability by summing the predicted probabilities for categories 3 (will definitely adopt) and 4 (already adopted) in the ordered logit model using the "predict" command via Stata 15. We interpret the probabilities as a set of rules that govern the behavior of BMP adoption in the near future and we convert the predicted probability to a binary adoption outcome following Lewis and Plantinga (2007). In particular, we draw a random number from uniform distribution $\mathrm{U}[0,1]$ and compare the predicted probability of adoption with this random number. If the predicted probability is larger than the random number, then we assume the farmer will adopt the BMP, otherwise, we assume the farmer will not adopt the BMP. We sum the land acres that are predicted to be operated by future adopters and divide it by the total acres across all surveyed producers in a given county. This generates the predicted land share of each BMP for each policy scenario at a county level. We run the economic model 500 times and examine the summary statistics for this land share of each county. The county means of the 500 runs are very close to what we use in the analysis, and standard deviations are all under 0.04 and sample variances are under 0.0012. Therefore, we are confident that our 
simulation results are representative. We use this predicted share to integrate these farmer land management predictions with the hydrological model, as explained in section 3.2.5.

In addition to the uniform cost-share payment, we also explore spatially targeted policies that only focus on the counties with highest level of nutrient runoff. Based on SWAT analysis, we identify the top $20 \%$ counties with highest total mass of TP or DRP runoff. With 3 counties overlapping on the two lists, we identify nine counties as the runoff "hotspots." "iii

\subsubsection{Fertilizer Demand Model}

To evaluate the effects of a fertilizer tax policy on commercial $\mathrm{P}$ fertilizer application rates, we estimate a fertilizer demand model. This reduced-form model is similar in spirit to the model presented at length in Zhang (2015). Our farmer survey is based on farmers' crop and nutrient management choices in 2013. This single-year data may not provide enough variation to reveal farmers' true demand elasticity of P fertilizers — over the past decade, the average U.S. P price index ranged from $\$ 300 /$ ton to $\$ 900 /$ ton. As a result, we added two hypothetical questions to induce farmers' responses under alternative P fertilizer price scenarios. Specifically, we ask “if commercial phosphorus fertilizer prices had been $\$ X /$ ton, what rate of $\mathrm{P}$ would you have applied on this field for this most recent crop? lbs/acre," in which $X$ could be 200, 250, 300, 350, $450,500,550,750,800,850$, or 900 , thus spanning the recent range of fertilizer price movements. With this information, we construct a reduced-form panel data model using $\mathrm{P}$ application rates under the actual price and two hypothetical price scenarios and identify the mean elasticity of P fertilizer demand. Specifically, the panel-data fixed-effects model of fertilizer demand is

$$
x_{i P l t}=\kappa_{P l 0}+\gamma_{P l 0} * \overline{r_{l P l t}}+\theta_{i l} \quad t=1,2,3
$$


where $\theta_{i l}$ is individual fixed effects; $\overline{r_{l P l t}}$ is the normalized $\mathrm{P}$ fertilizer prices adjusted by fertilizer types; $x_{i P l t}$ denotes the fertilizer application rate by farmer $i$ for each crop and fertilization frequency choice $l ; \kappa_{P l 0}$ is the intercept denoting the baseline application rate; and, $t$ represents the one actual and two hypothetical fertilizer price scenarios.

Previous research has demonstrated that farmers' fertilization choices depend on crop, crop rotation, and fertilizer application frequency choice (Zhang 2015). As a result, we estimate Eq. [2] separately for each of five combinations of crop and $\mathrm{P}$ application frequency choices (denoted by $l$ ) — corn and single year application (corn-single, cs), corn and multi-year application (corn-multi, cm), soybean and single year application (soybean-single, ss), soybean and multi-year application (soybean-multi, sm) and other crop choices (other, o). For each crop and fertilization frequency choice $l$, we can estimate the key parameter of interest-the mean coefficient for P fertilizer prices $\left(\widehat{\gamma_{P l 0}}\right)$. The estimated demand elasticity based on $\gamma_{P l 0}$ could be interpreted as a "sufficient statistic," as argued by Chetty (2009), which can be identified using reduced-form studies and then used to simulate policy changes and welfare effects for a fertilizer tax policy or a policy that couples fertilizer taxes with payments for conservation practices.

\subsubsection{Revenue-Neutral Hybrid Policy}

While single policies, be it cost-share payment or fertilizer tax, may not be sufficient to achieve the $40 \%$ reduction goal, we propose an innovative "revenue neutral" way to link the two types of policies to increase effectiveness - using the tax revenue as subsidy for BMP payments. We look for the optimal tax that minimizes loading by balancing the tradeoff between reduced fertilizer application and reduced revenue for BMP payment when tax is sufficiently high. For simplicity, 
we only focus on the payment for subsurface placement in our article because it is significantly more effective than cover crops.

Suppose the policymaker's goal is to minimize the P load to Lake Erie, and the revenue neutral policy uses the entire fertilizer tax revenue for cost-share payment. That is:

$$
\begin{gathered}
\min _{\tau} L=f(x(\tau))+g(B(R)) \\
\text { s.t. } R=\tau x(\tau)
\end{gathered}
$$

where $L$ is the total P runoff; $x$ is fertilizer applications on farms in the Maumee River watershed; $B$ is the quantity of BMPs applied on farms in the watershed; $\tau$ is fertilizer tax; and, $R$ is total fertilizer tax revenue. Based on our analysis, $f_{x}>0, g_{B}<0, x_{\tau}<0$, and $B_{R}>0$. That is, more fertilizer application leads to more P runoff, higher BMP adoption leads to lower P runoff, higher tax leads to lower fertilizer application, and higher tax revenue means higher total payment to BMPs, which leads to higher BMP adoption. To solve the runoff minimization problem, we set the first order condition:

$$
f_{x} x_{\tau}+g_{B} B_{R} R_{\tau}=0
$$

and derive the expression $R_{\tau}=-\frac{f_{x} x_{\tau}}{g_{B} B_{R}}<0$, which indicates that optimal tax should be set higher than the level that would maximize tax revenues. Eq [4] can be restated as

$$
f_{x} x_{\tau}+g_{B} B_{R}\left(x+\tau x_{\tau}\right)=0
$$

which implies that the optimal $\tau^{*}=-\frac{f_{x}}{g_{B} B_{R}}-\frac{x}{x_{\tau}}$. The $\frac{x}{x_{\tau}}$ term accounts for the offsetting effect of a reduction in $x$ on the amount of revenues available for BMP payments. This makes explicit the tradeoff that arises in setting the optimal tax to reduce loadings: increases in the tax will reduce fertilizer applications, but reductions in $x$ also reduce the total revenues available for BMP payments. This also clarifies how the optimal tax depends on the physical system: the greater the effectiveness of fertilizer reduction on reduced loadings, $f_{x}$, or the greater the effectiveness of the 
BMP in reducing loadings, $g_{B}$, the higher the optimal tax will be. However, the more responsive farmers are in the BMP adoption decisions to payments, the lower the optimal tax. Altogether this implies that the optimal tax is determined by a combination of behavioral and physical relationships. For some conditions, the optimal tax to reduce nutrient loadings may be a corner solution in which farmers demand for fertilizer is driven to zero.

This approach ignores other private and social costs of fertilizer reduction, including the forgone profits that may result from reduced fertilizer use. To account for these, we can reframe the problem by defining the optimal tax as the tax that equates the marginal social benefits (MSB) and marginal social costs (MSC) of fertilizer use. Suppose the marginal product of fertilizer in producing crops is $y_{x}$ and the average price of the crop is $p$. The MSB of fertilizer $x$ consists of the marginal private benefit, $p y_{x}$, as well as the marginal public benefits of increasing $x$, which are generated through the increase in tax revenues that support the cost-share payments for BMPs that reduce ecosystem damages by reducing loadings. Suppose $e_{L}$ represents the marginal damages of loadings to ecosystem services, then the marginal public benefits of $x$ are $e_{L} g_{B} B_{R} R_{x}$. The MSC consist of both marginal private cost to the farmer with the fertilizer tax $\tau$, $\mathrm{r}(1+\tau)$ where $\mathrm{r}$ is the fertilizer price, and a public cost, which is the ecosystem damages from loadings that result from a marginal increase in fertilizer applications, $e_{L} f_{x}$. Thus MSB=MSC implies:

$$
p y_{x}+e_{L} g_{B} B_{R} R_{x}=r(1+\tau)+e_{L} f_{x}
$$

Given $R_{x}=\tau$, the optimal tax that maximizes social net benefits is: $\tau_{S}^{*}=\frac{e_{L} f_{x}-p y_{x}+r}{e_{L} g_{B} B_{R}-r}$. Assuming that the public benefits from reducing nutrient loadings are sufficiently large, so that both the numerator and denominator are positive and $\tau^{*}>0$, then the optimal tax increases with the 
marginal ecosystem damages of fertilizer, decreases with the marginal effectiveness of BMP payments in reducing loadings, and decreases with the value of the marginal product of fertilizer.

In the empirical analysis, we implement the hybrid policy analyses by using the estimated fertilizer price elasticities to calculate the change in fertilizer use for a range of tax rates at the county level and sum up total tax revenues across the watershed. We then allocate the revenues for each of the tax scenarios as cost-share payments based on the most efficient payment level, defined as the one that leads to highest adoption rate (see Appendix D), and assume that it is administered in such a way that achieves this best possible outcome. Specifically, using the combined results of the farmer decision making and hydrological models, we plot changes in loadings as a function of the tax rate and compare the outcomes of tax only policies with the revenue neutral hybrid policies in Appendix D. We also show maps of the policy costs and tax burden for different counties under these uniform, targeted, or hybrid policies in Appendix E.

\subsubsection{Hydrologic Model - Soil and Water Assessment Tool (SWAT) Model}

SWAT is a watershed-scale model that has been continuously developed over the past 30 years by the U.S. Department of Agriculture (USDA) Agricultural Research Service (ARS) (Arnold et al. 1998; Gassman et al. 2007). SWAT incorporates a wide variety of biophysical characteristics such as topography, land use/cover, soil, and climate, and is able to facilitate farmer land management decisions such as fertilizer, crop, and tile drainage choices, and model changes in stream flow and the transport of nutrients (Arnold et al. 1998). Flow and nutrient transport processes within the SWAT model are routed at multiple scales. These scales, ranging from the smallest to the largest, include Hydrologic Response Unit (HRU), subbasin, and watershed levels. Although results can be derived and output from these multiple spatial scales, model 
processes exclude water, sediment, and nutrient flows across HRUs and instead are aggregated at the subbasin level and are routed across subbasins or through the stream phase of the model (Malagó et al., 2017).

The SWAT model has been extensively used to analyze how land use, agricultural management practices, and climate change affect water quality in Lake Erie (e.g., Bosch et al. 2014; Gildow et al. 2016; Michalak et al. 2013; Scavia et al. 2017). However, these biophysical studies assume large-scale or random adoption of conservation practices and do not link the physical process model with economic behavior assessing actual adoption by farmers, which makes it hard to predict the practicality and efficiency of the scenarios.

Building on Gebremariam et al. (2014), Gildow et al. (2016), and Kalcic et al. (2019), we build a spatially-explicit SWAT model calibrated to the western Lake Erie basin to simulate the hydrology and nutrient cycling of the Maumee River watershed. In particular, we delineate 358 sub-basins within the watershed, and further divide them into 24,256 HRUs based on spatial features in land use, soils, and topography (Kast 2018). Agricultural practices, including crop rotations, fertilizer applications, tillage practices, subsurface drainage, and other BMPs are incorporated in the model (at HRU-level) in consultation with the USDA-ARS, the Ohio State University Agriculture Extension personnel, and our previously-mentioned farmer survey (Burnett et al. 2015; Zhang et al. 2016). Key water quality data such as stream flow, TP, and DRP, as measured at the Waterville River gaging station, were obtained from the National Center for Water Quality Research at Heidelberg University. These data were used to calibrate the SWAT model from 2005 to 2010 at a satisfactory level (Moriasi et al. 2007).

\subsubsection{Linking Economic Models and SWAT for Policy Simulations}


For a fertilizer-tax policy, the linkages between the economic farmer decision making models and SWAT are simple. Specifically, a fertilizer tax results in higher effective fertilizer prices, which translate into predicted reduction in fertilizer application rates. The average predicted fertilizer rates at the township level are aggregated to the county level then randomly allocated to HRUs to obtain the HRU-average changes in $\mathrm{P}$ application rates to simulate changes in $\mathrm{P}$ loadings.

For the cost-share payment policies, we rely on the BMP adoption models outlined in section 3.2.2 to generate predicted changes in near-term BMP adoption decisions at the field level, which are converted to share of adopted acres by pooling across survey respondents at the county level. We then downscale the county-level predicted changes in adopted acreage share to the 358 sub-basins within the SWAT model, with an average of 4,834 acres per sub-basin. To do so, we assume that the predicted county-level land share of a given BMP, calculated as described in section 3.3, holds at a smaller spatial sub-basin level. We then randomly assign BMP adoption to each HRU within a sub-basin, using the predicted share of land acres as a constraint, so that the total share of land allocated to a given BMP corresponds to the predicted share at both subbasin and county level. With the newly developed SWAT model, we are able to divide the subbasins into finer scale spatial units of 24,256 HRUs, with an average size of 176 acres.

To evaluate the cost-effectiveness of different policy scenarios, we develop a tradeoff frontier that contrasts the policy costs incurred by governments with water quality outcomes measured in TP and DRP loading reductions. We assume that the policy costs for the cost-share programs are the total outlays of the cost-share payments to farmers, and assume that there are no additional program costs given the necessary program structure for administering these payments is already in place. In contrast, we assume there is administrative cost from the tax 
policies. Previous studies on the fertilizer tax policy implementations in Europe show that the uniform tax would cost $7 \%-10 \%$ of the tax revenue collected while monitoring a spatially differentiated fertilizer tax, assumed to be at the individual parcel or management unit, would cost $25 \%-30 \%$ of the tax revenue collected (Lankoski et al. 2010). Given that even our zonal policy is still quite aggregate in spatial scale, and therefore not nearly as administratively burdensome as a fully spatially differentiated tax, we assume a policy cost of $7 \%$ of the total tax revenues for the "tax only" policy scenarios and a slightly higher amount, $10 \%$, for the policy cost to implement, collect, and recycle the tax under the hybrid revenue-neutral policies. Note that because our current economic models do not explicitly model farmers' profit maximization decisions, our policy costs do not include the potential profit impacts induced by these BMP

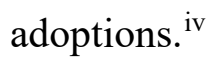

\section{Results and Discussions}

\subsection{BMP adoption changes under different policy scenarios}

Based on our analysis as described in 3.2.1, we define our baseline scenario as the predicted adoption rate without any policy interventions, which is about $51 \%$ adoption of subsurface placement and $20 \%$ adoption of cover crops (Table 2).

Following equation (1), we use the field- and farmer-specific adoption cost as an explanatory variable to estimate effects of socio-psychological, socio-economic, and field-level spatial characteristics on adoption choice. As previously explained, appendix $\mathrm{C}$ shows the results and procedures of how we calculate field- and farmer-specific adoption costs. Regression results from ordered logit models are odds ratios, which we translate to exponentiated coefficient estimates for easier understanding in Table 2. Note that although our objective is to understand 
and predict field-level adoption decisions under different policy interventions rather than causal identification, our prediction implicitly relies on the parameters on the adoption costs being correctly estimated. A higher adoption cost for subsurface placement or cover crops is hypothesized to lead to a lower probability of adopting these practices, which our results confirm - a $\$ 10$ increase in the adoption costs for fertilizer subsurface placement leads to a $24 \%$ decrease in the likelihood of adopting this practice in the future. Comparatively, a $\$ 10$ increase in field-level adoption cost for cover crops results in a $28 \%$ decrease in the future likelihood of adopting cover crops. One factor that consistently affects farmers' adoption decisions is the perceived efficacy of their conservation practices in reducing nutrient runoff. Perceived efficacy has a large positive impact on adoption decisions - a one unit increase in the perceived efficacy indicator almost doubles the likelihood of future adoption - confirming the finding of Zhang et al. (2016) and Wilson et al. (2019). We also find field acreage is positively correlated with BMP adoption decisions, possibly due to economies of scale. Other field and farmer characteristics do not have consistently significant impacts on farmer's adoption decisions. Farm income has opposite impacts on the adoption decision of subsurface placement and cover crops. These results could be explained by the intrinsic differences between these two BMPs and emphasize the heterogeneity among BMPs as well as farmers and fields, which is consistent with Zhang et al. (2016).

[Insert Table 2 Here: Ordered Logit Model Estimates of Subsurface Placement and Cover Crops Adoption] 
We aggregate the predicted adoption land share at county level for each payment scenario and present the average adoption rates (Figure 2a) measured in percentage of acres (adoption rate is the total acreage of adopted crop land divided by the total acreage of crop land). We see that with a $\$ 20 /$ acre to $\$ 80 /$ acre payment, the adoption rate of subsurface placement can increase from $46 \%$ to $65 \% .^{v}$ For cover crops, the adoption rate can increase from $20 \%$ to $63 \%$ of all cropland acres in the watershed.

[Insert Figure 2 Here: Increases in BMP adoptions under different nutrient management policy scenarios]

We also explore how fertilizer tax influences farmers' fertilizer amount decisions and report the results for the reduced-form panel data analysis equation (2) in Table 3. This model is estimated separately for each crop and fertilization frequency choice. The mean estimated elasticity of $\mathrm{P}$ fertilizer demand is derived from the coefficient for $p \_$price _norm, which is the estimated $\widehat{\gamma_{P l 0}}$ in equation (2), while holding all other variables constant at means. On average, the estimated elasticity of $\mathrm{P}$ fertilizer demand ranges from -0.264 to -0.488 . For example, there is a $2.64 \%$ reduction in $\mathrm{P}$ fertilizer rate given a $10 \%$ fertilizer price increase for corn fields with single-year fertilization. These estimates are similar to previous estimates of elasticity of fertilizer demand (Griliches 1958; Pitt 1983), which ranges from -0.20 to -0.95. A comparison of the elasticities across different fertilization frequency choices reveals that fields with multi-year fertilization application have a significantly higher elasticity of P demand than fields with singleyear application. This makes sense because farmers are more likely to use greater application rates with multi-year applications and could make flexible changes facing input price shocks. To 
evaluate the stability of our elasticity estimate, panel (II) only uses responses from these two hypothetical fertilizer application rate questions and assesses the effects of potential "hypothetical bias" on the estimated coefficient in P fertilizer prices. The implied elasticities are very similar to the main specification, except for corn with multi-year applications, which is also within the range of previous estimates from the literature.

[Insert Table 3 Here: Estimated elasticity of phosphorus fertilizer demand from reduced-form panel regressions]

\subsection{P loadings under different policy scenarios through Linkage with SWAT Model}

To link the predicted adoption rate under each policy scenario with SWAT, we randomly allocate the adoption rate within each county across 24,256 HRUs while maintaining the predicted adoption rate at the targeted level for each sub-basin. HRUs are the smallest spatial units at which hydrologists can identify nutrient flow in the SWAT model. Simulations generate monthly TP and DRP runoff from 2005 to 2015 (with 2000 to 2004 as the validation period) and we calculate the yearly spring (March to July) load to match the 2012 GLWQA $\operatorname{target}^{\mathrm{vi}}$. Figure 2 shows the average spring load change under each policy.

In Figure 3a we show the percentage reduction in spring TP and DRP loadings under uniform or targeted cost-share payments for subsurface placement. With uniform payments ranging from $\$ 20$ to $\$ 80$ per acre, a gain in adoption rate for subsurface placement from $46 \%$ to $65 \%$ results in load reductions of $8 \%$ in TP and $13 \%$ in DRP. The figure shows that the same level of total cost-share payment budget can achieve a much higher P reduction when targeting the runoff hotspots counties, which also enables higher payments. Figure $3 \mathrm{~b}$ shows uniform 
payments but for cover crops where we see negligible P reductions of less than 1\%. A number of factors could be responsible for the negligible impact of cover crops on phosphorus reductions, including model specification of the timing between removing cover crops and planting the next crop in rotation. In the SWAT model, the time between the removal of cover crops and the planting of corn was 22 days. During this time the soil is bare and without cover, which could lead to more nutrient discharge than if the soil was covered (Zhang et al., 2011). Some previous literature is consistent with the negligible effect of cover crops on phosphorus reductions (e.g. King et al. in prep), while other studies have found much larger effects on reducing phosphorus losses from increased cover crop adoption (Duncan et al., 2019; Singh et al., 2018; Iowa Nutrient Reduction Strategy 2017; Heathwaite et al., 2000; Sharpley and Smith, 1991). ${ }^{\text {vi }}$

In Figures $3 \mathrm{c}$ and $3 \mathrm{~d}$ we show respectively the percentage reduction for various levels of a fertilizer tax and the revenue-neutral hybrid policy in which the revenues from the fertilizer tax are used as BMP payments. The results clearly demonstrate that the hybrid policy is more effective than either a standalone fertilizer tax or cost-share policy. For example, at a $200 \%$ $(400 \%)$ tax rate, we find that the reduction in TP and DRP is $22.5 \%(40 \%)$ and $29 \%(51 \%)$ respectively for the tax-only scenarios and $40.5 \%(54 \%)$ and $53 \%$ (69\%) for the hybrid policy scenarios. By comparison, if taxpayer dollars were used to generate the same amount of funds for cost-share payments for subsurface placement as is generated by a $200 \%$ fertilizer tax, then this would correspond to a $\$ 170$ per acre uniform payment with estimated adoption rates of $72 \%$ and load reductions of $18 \%$ in TP and $24 \%$ in DRP.

[Insert Figure 3 Here: Reduction in total and DRP loadings under different nutrient management policy scenarios] 


\subsection{Tradeoff frontier analysis of different nutrient management policies}

We establish the policy tradeoff frontier by contrasting the predicted DRP and TP reduction rate with the cost of each policy incurred by governments to evaluate the cost-effectiveness of each policy (Figure 4). As explained in section 3.2.5, we calculate only the direct government outlays as the policy costs. Therefore, the total cost-share payments are the policy costs for the voluntary BMP adoption programs. Recall we assume that the policy costs for the fertilizer tax and hybrid tax/cost-share policies are 7 and $10 \%$ of the tax revenue, respectively. Figure 4 clearly demonstrates that the revenue-neutral combination policy of allocating tax revenue as payment for subsurface placement is the most cost-effective policy. Not surprisingly, because this is a revenue-neutral policy, it dominates any cost share payment program that imposes the policy cost on taxpayers. Because it not only raises the cost of pollution, but also increases BMP adoption by providing cost-share payments, the hybrid policy generates additional water quality gains relative to the fertilizer tax scenarios in which revenues are not redistributed in this way.

[Insert Figure 4 Here: Tradeoff frontier of DRP loading reductions versus policy costs under different nutrient management policies]

\section{Conclusions}

HABs and hypoxia in freshwater and marine ecosystems are a growing global concern. In the United States, HABs in Lake Erie have worsened since the 1990s - the five worst blooms on record all occurred since 2011 (Wilson et al. 2019). The size of the hypoxic zone in the Gulf of Mexico is not smaller despite decades of nutrient reduction efforts. Previous research has 
decidedly linked agricultural nutrient runoffs with these downstream water quality problems. Our article focuses on the cost-effectiveness of various nutrient management policies in reducing nutrient runoff by developing a spatially integrated economic-hydrological model of the western Lake Erie basin. Our integrated model combines economic analysis of micro-level farmer adoption behavior of three key BMPs—subsurface placement, cover crops, and reduced P fertilizer applications - with a hydrological model, which allows us to quantify changes in individual BMP adoptions and watershed-scale P loadings. Our results show that subsurface placements and $\mathrm{P}$ application rate reductions are more cost-effective than cover crops, and that a hybrid revenue-neutral policy, which applies fertilizer tax revenue as a cost-share payment for subsurface placement, is a far more cost-effective approach in achieving the desired improvements in water quality. We also find that, despite substantial increases in the adoption of single BMPs with increases in cost-share payments, the reductions in P are far below the $40 \%$ reduction goal. In contrast, the tax or hybrid policies can achieve the policy target and in a much more cost-effective manner. For example, a $400 \%$ fertilizer tax could lead to $39.5 \%$ reduction in TP, while a hybrid policy in which a $200 \%$ fertilizer tax is applied and recycled for cost-share payments for subsurface placement can lead to $40.5 \%$ reduction in TP.

Our findings have important implications for the design of nutrient management policies and integrated assessment models of nutrient runoff and water quality. In particular, our results show that by ignoring biophysical complexities, such as legacy P in the soils captured through biophysical process models such as SWAT, economic adoption models alone could significantly overestimate the effectiveness of these policies in reducing nutrient runoffs. We also demonstrate the importance of broadening the policy toolbox and moving beyond the prevalent cost-share payments to consider more cost-effective policy instruments such as a hybrid fertilizer tax/cost- 
share payments program. This revenue-neutral combination policy not only induces fertilizer rate reductions, but also generates revenues that can be used for cost-share payment programs. Despite still being second best, ${ }^{\text {vii }}$ this makes it more cost-effective compared to the cost-share payment programs. Even the spatially targeted zonal policies, while more cost-effective than uniform payments, are far less cost-effective than the hybrid policies.

Our article represents a step toward better understanding the complex coupled humannatural systems of agricultural pollution and water quality and ecosystem services; however, it has several key limitations. First, we do not conduct a complete cost-benefit analysis, which would account for additional private and public benefits and costs, including potential foregone profits from reduced fertilizer applications that may result in lower yields and the corresponding increases in ecosystem service benefits from water quality improvements in Lake Erie. Future research is needed to incorporate benefits, such as Lake Erie recreational anglers' willingness to pay (Zhang and Sohngen 2018), by combining them with lake ecological models and non-market valuation. Such studies could fully examine the tradeoff between fertilizer reduction and reduction in cost-share payments when tax is sufficiently high. Second, in terms of spatially targeted policies, we only explore the zonal policies that target runoff hotspot counties, but not at an individual field level, which would be necessary to establish the first-best policy benchmark. Third, future research needs to evaluate how to mitigate the potential bias resulting from the spatial and temporal mismatch when the predicted annual adoption behaviors are aggregated to the county level and the biophysical models generate daily or monthly water quality simulations at a much finer scale. 
Acknowledgements: This work was supported by the National Science Foundation Coupled Human and Natural Systems program [grant number GRT00022685] and the Innovations at the Nexus of Food, Energy and Water Systems program [grant number 1739909] and the Ohio Sea Grant program [grant number R/ME-038]. We thank Robyn Wilson, Nathan Cook, and participants at the Social Costs of Water Quality Workshop at Cornell University and Agricultural \& Applied Economics Association (AAEA) annual meetings for comments and suggestions on an earlier draft. 


\section{References}

Arbuckle, J.G. 2013. “Farmer support for extending conservation compliance beyond soil erosion: Evidence from Iowa." Journal of Soil and Water Conservation 68(2): 99-109.

Arnold, J.G., R. Srinivasan, R.S. Muttiah, and J.R. Williams. 1998. "Large area hydrologic modeling and assessment part I: Model development." Journal of the American Water Resources Association 34(1): 73-89.

Binational.net (Canada-United States Collaboration for Great Lakes Water Quality). 2012. "The 2012 Great Lakes water quality agreement (GLWQA).” Available at https://binational.net/2012/09/05/2012-glwqa-aqegl/

Blackstock, K.L., J. Ingram, R. Burton, K.M. Brown, and B. Slee. 2010. “Understanding and influencing behavior change by farmers to improve water quality." Science of the Total Environment 408(23): 5631-5638.

Bosch, N.S., M.A. Evans, D. Scavia, and J.D. Allan. 2014. "Interacting effects of climate change and agricultural BMPs on nutrient runoff entering Lake Erie.” Journal of Great Lakes Research 40(3): 581-589.

Burnett, E.A., R.S. Wilson, B. Roe, G. Howard, E.G. Irwin, W. Zhang, J. Martin. 2015. "Farmers, phosphorus and water quality: Part II. A descriptive report of beliefs, attitudes and best management practices in the Maumee watershed of the western Lake Erie basin.” The Ohio State University, School of Environment \& Natural Resources, Columbus, $\mathrm{OH}$.

Claassen, R., and Horan, R.D. 2001. "Uniform and non-uniform second-best input taxes." Environmental and Resource Economics 19(1):1-22. 
Chetty, R. 2009. "Sufficient statistics for welfare analysis: a bridge between structural and reduced-form methods." Annual Review of Economics 1(1): 451-488.

Dillman, D.A. 2011. Mail and Internet Surveys: The Tailored Design Method--2007 Update with New Internet, Visual, and Mixed-Mode Guide. New Jersey: John Wiley \& Sons.

Duncan, E., King, K., Hanrahan, B., Shedekar, V.S. 2019. “Cover crops and nutrient loss from the edge-of-field network in Northwest Ohio." Agriculture, ecosystems and environment. Under review.

Garnache, C., S.M. Swinton, J.H. Herriges, F. Lupi, and R.J. Stevenson. 2016. “Solving the phosphorus pollution puzzle: synthesis and directions for future research.” American Journal of Agricultural Economics 98(5): 1334-1359.

Gassman, P.W., M.R. Reyes, C.H. Green, and J.G. Arnold. 2007. "The soil and water assessment tool: Historical development, applications, and future research directions." Center for Agricultural and Rural Development, Iowa State University.

Gebremariam, S.Y., J.F. Martin, C. DeMarchi, N.S. Bosch, R. Confesor, and S.A. Ludsin. 2014.

"A comprehensive approach to evaluating watershed models for predicting river flow regimes critical to downstream ecosystem services." Environmental Modelling \& Software 61: 121-134.

Gildow, M., N. Aloysius, S. Gebremariam, and J. Martin. 2016. "Fertilizer placement and application timing as strategies to reduce phosphorus loading to Lake Erie." Journal of Great Lakes Research 42(6): 1281-1288.

Griliches, Z. 1958. "The demand for fertilizer: an economic interpretation of a technical change.” Journal of Farm Economics 40: 591-606. 
Heathwaite, A. L., \& Dils, R. M. (2000). Characterising phosphorus loss in surface and subsurface hydrological pathways. Science of the Total Environment, 251, 523-538.

Huang, W.Y., R.G. Heifner, H. Taylor, and N.D. Uri. 2000. “Enhancing nitrogen fertilizer application timing by insurance.” Journal of Sustainable Agriculture 16(1): 31-57.

Iowa Nutrient Reduction Strategy: A science and technology-based framework to assess and reduce nutrients to Iowa waters and the Gulf of Mexico. Available at: http://www.nutrientstrategy.iastate.edu/sites/default/files/documents/2017\%20INRS\%20 Complete Revised\%202017 12_11.pdf

Kalcic, M.M.C.; Kirchhoff, C.; Bosch, N.; Muenich, R.L.; Murray, M.; Griffith Gardner, J.; Scavia, D. 2016. "Engaging Stakeholders to Define Feasible and Desirable Agricultural Conservation in Western Lake Erie Watersheds.” Environmental Science and Technology 50 (15): 8135-8145.

Kalcic, M. M., Muenich, R. L., Basile, S., Steiner, A. L., Kirchhoff, C., \& Scavia, D. (n.d.). "Climate change and nutrient loading: warming can counteract a wetter future." Environmental Science \& Technology.

Kast, J.B. 2018. "Manure management in the Maumee River watershed and watershed modeling to assess impacts on Lake Erie's water quality." Master's thesis, The Ohio State University, Columbus, $\mathrm{OH}$.

Kelley, K.W. and D.W. Sweeney. 2005. "Tillage and urea ammonium nitrate fertilizer rate and placement affects winter wheat following grain sorghum and soybean.” Agronomy Journal 97(3): 690-697. 
Kurkalova, L., C. Kling, and J. Zhao. 2006. "Green subsidies in agriculture: estimating the adoption costs of conservation tillage from observed behavior." Canadian Journal of Agricultural Economics/Revue canadienne d'agroeconomie 54: 247-267.

Lake Erie LaMP. 2011. "Lake Erie binational nutrient management strategy: Protecting Lake Erie by managing phosphorus.” Lake Erie LaMP Work Group Nutrient Management Task Group.

Lankoski, J., Lichtenberg, E., \& Ollikainen, M. (2010). Agri-environmental program compliance in a heterogeneous landscape. Environmental and Resource Economics, 47(1), 1-22.

Larson, D.M., Helfand, G.E., and House, B.W. 1996. "Second-best tax policies to reduce nonpoint source pollution.” American Journal of Agricultural Economics, 78(4): 11081117.

Laukkanen, M., and C. Nauges. 2014. "Evaluating greening farm policies: A structural model for assessing agri-environmental subsidies." Land Economics 90: 458-481.

Lewis, D.J., and A.J. Plantinga. 2007. "Policies for habitat fragmentation: Combining econometrics with GIS-based landscape simulations." Land Economics 83(2): 109-127.

Maccoux, M.J., A. Dove, S.M. Backus, and D.M. Dolan. 2016. “Total and soluble reactive phosphorus loadings to Lake Erie: A detailed accounting by year, basin, country, and tributary." Journal of Great Lakes Research 42(6): 1151-1165.

Mahler, R.L. 2001. “Fertilizer placement.” CIS 757, University of Idaho.

Malagó, A., Bouraoui, F., Vigiak, O., Grizzetti, B., \& Pastori, M. (2017). Modelling water and nutrient fluxes in the Danube River Basin with SWAT. Science of the Total Environment, 603, 196-218. 
Martin, J., E.G. Irwin, R. Wilson, S. Ludsin, and E. Toman. 2011. “CNH: Co-Evolution of Upstream Human Behavior and Downstream Ecosystem Services in a Changing Climate.” Funder: Directorate for Social, Behavioral \& Economic Sciences (NSF SBE).

McGuire, J., L.W. Morton, J.G. Arbuckle, and A. Cast. 2015. "Farmer identities and responses to the social-biophysical environment.” Journal of Rural Studies 39: 145-155.

Michalak, A.M., E.J. Anderson, D. Beletsky, S. Boland, N.S. Bosch, T.B. Bridgeman, J.D. Chaffin, K. Cho, R. Confesor, I. Daloğlu, and J.V. DePinto. 2013. "Record-setting algal bloom in Lake Erie caused by agricultural and meteorological trends consistent with expected future conditions." Proceedings of the National Academy of Sciences 110(16): $6448-6452$.

Moriasi, D.N., J.G. Arnold, M.W. Van Liew, R.L. Binger, R.D. Harmel, and T.L. Veith. 2007. "Model evaluation guidelines for systematic quantification of accuracy in watershed simulations." Transactions of the ASABE 50(3): 885-900.

Norris, P.E., and S.S. Batie. 1987. "Virginia farmers' soil conservation decisions: An application of tobit analysis." Southern Journal of Agricultural Economics 19: 79-90.

Pitt, M.M. 1983. "Farm-level fertilizer demand in Java: A meta-production function approach." American Journal of Agricultural Economics 65: 502-508.

Rabotyagov, S.S., T.D. Campbell, M. White, J.G. Arnold, J. Atwood, M.L. Norfleet, C.L. Kling, P.W. Gassman, A. Valcu, J. Richardson, R.E. Turner, and N.N. Rabalais. 2014. “Costeffective targeting of conservation investments to reduce the northern Gulf of Mexico hypoxic zone." Proceedings of the National Academy of Sciences 111: 18530-18535.

Rabotyagov, S. S., Valcu, A. M., \& Kling, C. L. (2014). Reversing property rights: practicebased approaches for controlling agricultural nonpoint-source water pollution when 
emissions aggregate nonlinearly. American Journal of Agricultural Economics, 96(2), 397-419.

Ruffatti, M. D., Roth, R. T., Lacey, C. G., \& Armstrong, S. D. (2019). Impacts of nitrogen application timing and cover crop inclusion on subsurface drainage water quality. Agricultural Water Management, 211, 81-88.

Scavia, D., J.D. Allan, K.K. Arend, S. Bartell, D. Beletsky, N.S. Bosch, S.B. Brandt, R.D. Briland, I. Daloğlu, J.V. DePinto, and D.M. Dolan. 2014. "Assessing and addressing the re-eutrophication of Lake Erie: Central basin hypoxia." Journal of Great Lakes Research 40(2): 226-246.

Scavia, D., M. Kalcic, R. Logsdon Muenich, N. Aloysius, I. Bertani, C. Boles, R. Confesor, J. DePinto, M. Gildow, J. Martin, J. Read, T. Redder, D. Robertson, S. Sowa, Y. Wang, and H. Yen. 2017. "Multiple SWAT models guide strategies for agricultural nutrient reductions." Frontiers in Ecology and the Environment 15(3): 126-132.

Segerson, K., \& Wu, J. (2006). Nonpoint pollution control: Inducing first-best outcomes through the use of threats. Journal of Environmental Economics and Management, 51(2), 165184.

Sharpley, A. N., Smith, S. J., \& Hargrove, W. L. (1991). Effects of cover crops on surface water quality. Cover crops for clean water, 41-49.

Sheriff, G. 2005. "Efficient waste? Why farmers over-apply nutrients and the implications for policy design.” Review of Agricultural Economics 27(4): 542-557.

Shortle, J., \& Horan, R. D. (2013). Policy instruments for water quality protection. Annu. Rev. Resour. Econ., 5(1), 111-138. 
Shortle, J. S., Ribaudo, M., Horan, R. D., \& Blandford, D. (2012). Reforming agricultural nonpoint pollution policy in an increasingly budget-constrained environment. Environmental science \& technology, 46(3), 1316-1325.

Singh, G., Williard, K. W., \& Schoonover, J. E. (2018). Cover crops and tillage influence on nitrogen dynamics in plant-soil-water pools. Soil Science Society of America Journal, 82(6), 1572-1582.

Sohngen, B., K.W. King, G. Howard, J. Newton, and D.L. Forster. 2015. "Nutrient prices and concentrations in Midwestern agricultural watersheds." Ecological Economics 112: 141149.

Stumpf, R.P., T.T. Wynne, D.B. Baker, and G.L. Fahnenstiel. 2012. "Interannual variability of cyanobacterial blooms in Lake Erie.” PLoS One 7(8): e42444.

Stumpf, R.P., L.T. Johnson, T.T. Wynne, and D.B.Baker. 2016. “Forecasting annual cyanobacterial bloom biomass to inform management decisions in Lake Erie.” Journal of Great Lakes Research 42(6): 1174-1183.

Thapa, R., Mirsky, S. B., \& Tully, K. L. (2018). Cover crops reduce nitrate leaching in agroecosystems: A global meta-analysis. Journal of environmental quality, 47(6), 14001411.

U.S. Department of Agriculture. 2014. "Census of Agriculture 2012: Volume 1, Chapter 2: State Level Data.” National Agricultural Statistics Service, available online at https://www.nass.usda.gov/Publications/AgCensus/2012/Full_Report/Volume_1,_Chapte r_2_US_State_Level/ 
U.S. Department of Agriculture Natural Resource Conservation Service (USDA NRCS). 2016. “Western Lake Erie Basin Imitative." available online at https://www.nrcs.usda.gov/wps/portal/nrcs/detail/null/?cid=nrcs144p2 031032

U.S. Department of Agriculture Natural Resource Conservation Service (USDA NRCS). 2018. “EQIP Total Obligations, by Fiscal Year 2009-2018.” available online at https://www.nrcs.usda.gov/Internet/NRCS_RCA/reports/fb08_cp_eqip.html

Weinberg, M., \& Kling, C.L. 1996. "Uncoordinated agricultural and environmental policy making: An application to irrigated agriculture in the West." American Journal of Agricultural Economics 78(1): 65-78.

Wilson, R.S., M.A. Beetstra, J.M. Reutter, G. Hesse, K.M. DeVanna Fussell, L.T. Johnson, K.W. King, G.A. LaBarge, J.F. Martin, and C. Winslow. 2019. “Commentary: Achieving phosphorus reduction targets for Lake Erie.” Journal of Great Lakes Research 45(1): 411.

Wu, J.J., R.M. Adams, C.L. Kling, and K. Tanaka. 2004. "From microlevel decisions to landscape changes: An assessment of agricultural conservation policies." American Journal of Agricultural Economics 86: 26-41.

Zhang, W., R.S. Wilson, E. Burnett, E.G. Irwin, and J.F. Martin. 2016. "What motivates farmers to apply phosphorus at the "right" time? Survey evidence from the western Lake Erie basin.” Journal of Great Lakes Research 42(6): 1343-1356.

Zhang, W. 2015. "Three essays on land use, land management, and land values in the agroecosystem." Ph.D. Dissertation, The Ohio State University. 
Zhang, W., and B. Sohngen. 2018. "Do US anglers care about harmful algal blooms? A choice experiment of Lake Erie recreational anglers.” American Journal of Agricultural Economics 100(3): 868-888. 
Tables

Table 1. Variable Descriptions and Summary Statistics

\begin{tabular}{|c|c|c|c|c|c|c|}
\hline Variable & Description & \# Obs. & Mean & Std. Dev. & Min & Max \\
\hline \multicolumn{7}{|l|}{ Farmer choice } \\
\hline Adopt_place & $\begin{array}{l}\text { The attitude of adopting subsurface } \\
\text { placement ( } 0 \text { "will never adopt," } 1 \\
\text { "unlikely to adopt," } 2 \text { "likely to adopt," } 3 \\
\text { "will definitely adopt," and to } 4 \text { "have } \\
\text { already adopted") }\end{array}$ & 2134 & 2.65 & 1.25 & 0 & 4 \\
\hline Adopt_cover & $\begin{array}{l}\text { The attitude of adopting cover crops (0 } \\
\text { "will never adopt," } 1 \text { "unlikely to adopt," } 2 \\
\text { "likely to adopt," } 3 \text { "will definitely adopt," } \\
\text { and } 4 \text { "have already adopted") }\end{array}$ & 2142 & 1.96 & 1.13 & 0 & 4 \\
\hline$P_{-}$rate & $\begin{array}{l}\mathrm{P} \text { fertilizer rate }\left(\mathrm{lbs} / \text { acre of } \mathrm{P}_{2} \mathrm{O}_{5} \text { applied in }\right. \\
2013)\end{array}$ & 1488 & 100.07 & 252.84 & 0 & 300 \\
\hline$P \_$price_actual & Actual P fertilizer price (\$/ton) & 1489 & 576.20 & 107.24 & 375 & 800 \\
\hline $\mathrm{P} \_$price_hypothetical & Hypothetical P fertilizer price (\$/ton) & 1489 & 367.60 & 157.17 & 200 & 950 \\
\hline \multicolumn{7}{|c|}{ Socio-psychological characteristics } \\
\hline Efficacy_placement & $\begin{array}{l}\text { Perceived effectiveness of adopting subsur } \\
\text { face placement at reducing nutrients ( } 0 \text { " } \mathrm{n} \\
\text { ot at all" to } 4 \text { "to a great extent") }\end{array}$ & 2189 & 2.59 & 0.97 & 0 & 4 \\
\hline Efficacy_cover & $\begin{array}{l}\text { Perceived effectiveness of adopting cover } \\
\text { crops at reducing nutrients ( } 0 \text { "not at all" t } \\
\text { o } 4 \text { "to a great extent") }\end{array}$ & 2197 & 2.56 & 1.01 & 0 & 4 \\
\hline Perception_control & $\begin{array}{l}\text { Farmers' perception of } \\
\text { control over the farm ( } 0 \text { "no control" to } 6 \\
\text { "complete control") }\end{array}$ & 2189 & 3.49 & 1.02 & 0 & 6 \\
\hline
\end{tabular}


Risk_mean

Farmer_identity
Risk attitude in general ( 0 "not willing to $\mathrm{t}$ ake risks" to 10 "very willing to take risk s")

Farmer identity (ranges from -4 "greatest identity as productionist" to 4 "greatest ide ntity as conservationist")

Socio-economic characteristics

Age

Farm_income

Age (years)

annual gross farm

income (2013 dollars) ( 1 “< $<50,000$, , 2

“\$50,000-99,999," 3 “100,000-\$249,99

9," 4 “250,000-499,999," 5 ">500,000”)
2198

.17

2.09

0

10

Field-level characteristics field acre

Slope
Soil_quality
Acreage of the field

Soil quality of the field (1 "low," 2 "mediu m," 3 "high")

Slope of the field ( 1 " $0 \%-2 \%, " 2$ " $2 \%$ $5 \%$," 3 "5\%-10\%," 4 " >10\%," 5 "not sur

e")

Binary, $=1$ if field is rented
2227

2039

58.16

3.05

11.87

1.33

17

85

5

2227

51.65

2.02

49.13

.82

5

2197

1.43

5

2204

.48

0

1 
Table 2. Ordered Logit Model Estimates of Subsurface Placement and Cover Crops Adoptions

\begin{tabular}{|c|c|c|}
\hline Variables & Adopt subsurface placement & Adopt cover crops \\
\hline \multicolumn{3}{|l|}{ Psychological-demographic characteristics } \\
\hline Perceived_efficacy_of_subsurface_placement & $\begin{array}{l}0.7103 * * * \\
(0.061)\end{array}$ & \\
\hline Perceived_efficacy_of_cover_crops & & $\begin{array}{c}0.8700 * * * \\
(0.057)\end{array}$ \\
\hline Perception_control & $\begin{array}{l}0.0536 \\
(0.056)\end{array}$ & $\begin{array}{l}0.0552 \\
(0.051)\end{array}$ \\
\hline Risk_mean & $\begin{array}{l}0.0168 \\
(0.027)\end{array}$ & $\begin{array}{l}0.0294 \\
(0.025)\end{array}$ \\
\hline Farmer_identiy & $\begin{array}{l}-0.0182 \\
(0.066)\end{array}$ & $\begin{array}{c}0.1631^{* * *} \\
(0.062)\end{array}$ \\
\hline \multicolumn{3}{|l|}{ Socio-economic characteristics } \\
\hline Age & $\begin{array}{c}0.0001^{*} \\
(0.003)\end{array}$ & $\begin{array}{c}-0.0110^{* *} \\
(0.003)\end{array}$ \\
\hline Farm_income & $\begin{array}{c}-0.0832 * * * \\
(0.045)\end{array}$ & $\begin{array}{c}0.1064 * * * \\
(0.041)\end{array}$ \\
\hline \multicolumn{3}{|l|}{ Field-level spatial characteristics } \\
\hline Subsurface_placement_cost & $\begin{array}{c}-0.2416^{* * * *} \\
(0.015)\end{array}$ & \\
\hline Cover_crops_cost & & $\begin{array}{c}-0.2835^{* * *} \\
(0.021)\end{array}$ \\
\hline Field_acre & $\begin{array}{c}0.0031 * * * \\
(0.001)\end{array}$ & $\begin{array}{c}0.0021^{* *} \\
(0.001)\end{array}$ \\
\hline Soil_quality & $\begin{array}{l}0.0907 \\
(0.067)\end{array}$ & $\begin{array}{l}0.0282 \\
(0.060)\end{array}$ \\
\hline Slope & $\begin{array}{l}-0.0407 \\
(0.039)\end{array}$ & $\begin{array}{l}-0.0260 \\
(0.036)\end{array}$ \\
\hline Field_rent & $\begin{array}{l}0.0718 \\
(0.117)\end{array}$ & $\begin{array}{l}0.0069 \\
(0.108)\end{array}$ \\
\hline Fixed effect & County level & County level \\
\hline Observations & 1,796 & 1,801 \\
\hline Average baseline adoption rate - Maumee & $51.1 \%$ & $19.7 \%$ \\
\hline Average baseline adoption rate - IN & $46.1 \%$ & $14.0 \%$ \\
\hline Average baseline adoption rate - MI & $52.2 \%$ & $24.7 \%$ \\
\hline Average baseline adoption rate $-\mathrm{OH}$ & $52.6 \%$ & $20.9 \%$ \\
\hline
\end{tabular}


Table 3. Estimated Elasticity of Phosphorus (P) Fertilizer Demand from Reduced-Form Panel Regressions

\begin{tabular}{|c|c|c|c|c|}
\hline & $\begin{array}{l}\text { corn } \\
\text { single }\end{array}$ & $\begin{array}{l}\text { corn } \\
\text { multi }\end{array}$ & $\begin{array}{l}\text { soybean } \\
\text { single }\end{array}$ & $\begin{array}{l}\text { soybean } \\
\text { multi }\end{array}$ \\
\hline \multicolumn{5}{|l|}{ Linear panel fixed effects model } \\
\hline Actual and hypothetical & $-0.4376^{*}$ & $-0.5634 * * *$ & $-0.4104 * * *$ & $-0.8462 * * *$ \\
\hline P price & $(0.2259)$ & $(0.1689)$ & $(0.1111)$ & $(0.2325)$ \\
\hline Intercept & $\begin{array}{l}115.89 * * * \\
(12.77)\end{array}$ & $\begin{array}{l}112.47^{* * *} \\
(9.43)\end{array}$ & $\begin{array}{l}109.52 * * * \\
(6.186)\end{array}$ & $\begin{array}{l}148.71 * * * \\
(13.39)\end{array}$ \\
\hline Number of observations & 1752 & 1097 & 603 & 405 \\
\hline Implied mean elasticity & $-0.2714^{*}$ & $-0.388 * * *$ & $-0.2638 * * *$ & $-0.4876^{* * *}$ \\
\hline \multicolumn{5}{|c|}{ Linear panel fixed effects model - Hypothetical questions only } \\
\hline Hypothetical & $-0.4682 * * *$ & $-0.3616^{* * *}$ & $-0.3561 * * *$ & $-0.8307 * * *$ \\
\hline P price & $(0.1554)$ & $(0.1063)$ & $(0.1012)$ & $(0.2620)$ \\
\hline Intercept & $\begin{array}{l}124.65^{* * *} \\
(8.71)\end{array}$ & $\begin{array}{l}100.82^{* * *} \\
(5.84)\end{array}$ & $\begin{array}{l}112.63^{* * *} \\
(5.559)\end{array}$ & $\begin{array}{l}155.93 \\
(14.990)\end{array}$ \\
\hline Number of observations & 1168 & 731 & 402 & 270 \\
\hline Implied mean elasticity & $-0.2665 * * *$ & $-0.2456 * * *$ & $-0.2101 * * *$ & $-0.4383 * * *$ \\
\hline $\begin{array}{l}\text { Average actual } \mathrm{P} \text { application rate } \\
(\mathrm{lbs} / \mathrm{ac})\end{array}$ & 106.22 & 123.95 & 109.35 & 112.03 \\
\hline
\end{tabular}




\section{Figures}

Figure 1. Map of the Maumee River watershed highlighting the per-acre phosphorus loading across subbasins.

\section{Figure 1. The Maumee River Watershed}

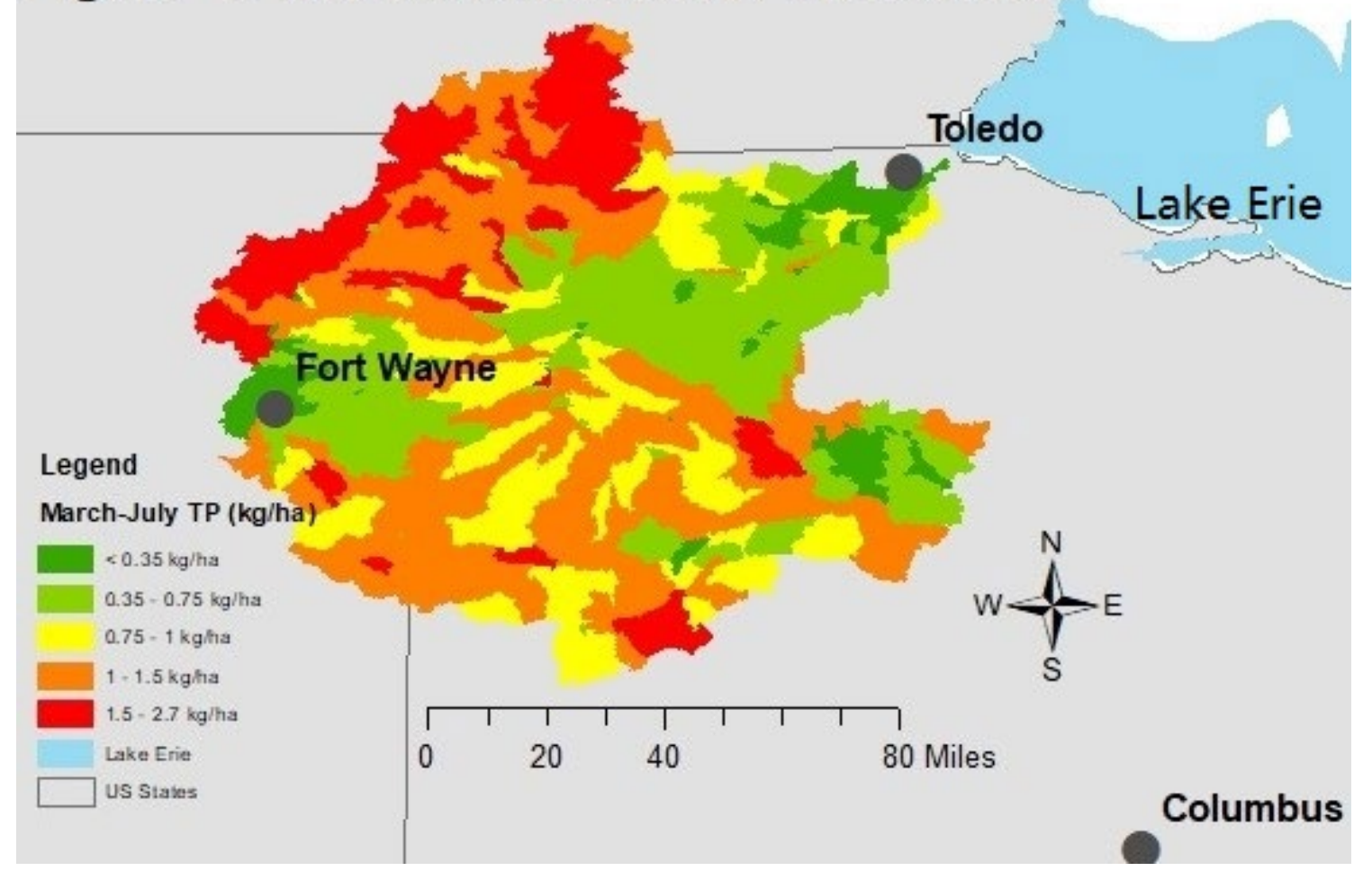


Figure 2. Increases in BMP adoptions under different nutrient management policy scenarios.
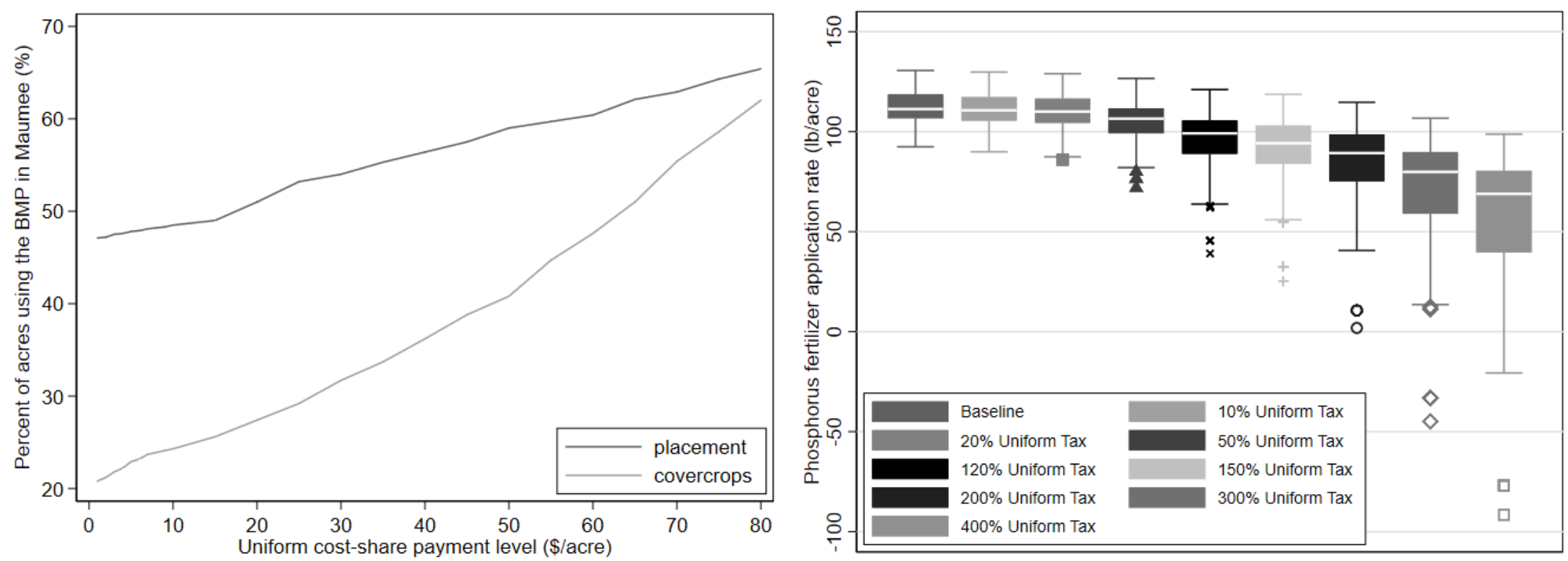
Figure 3. Reduction in total and DRP loadings under different nutrient management policy scenarios.
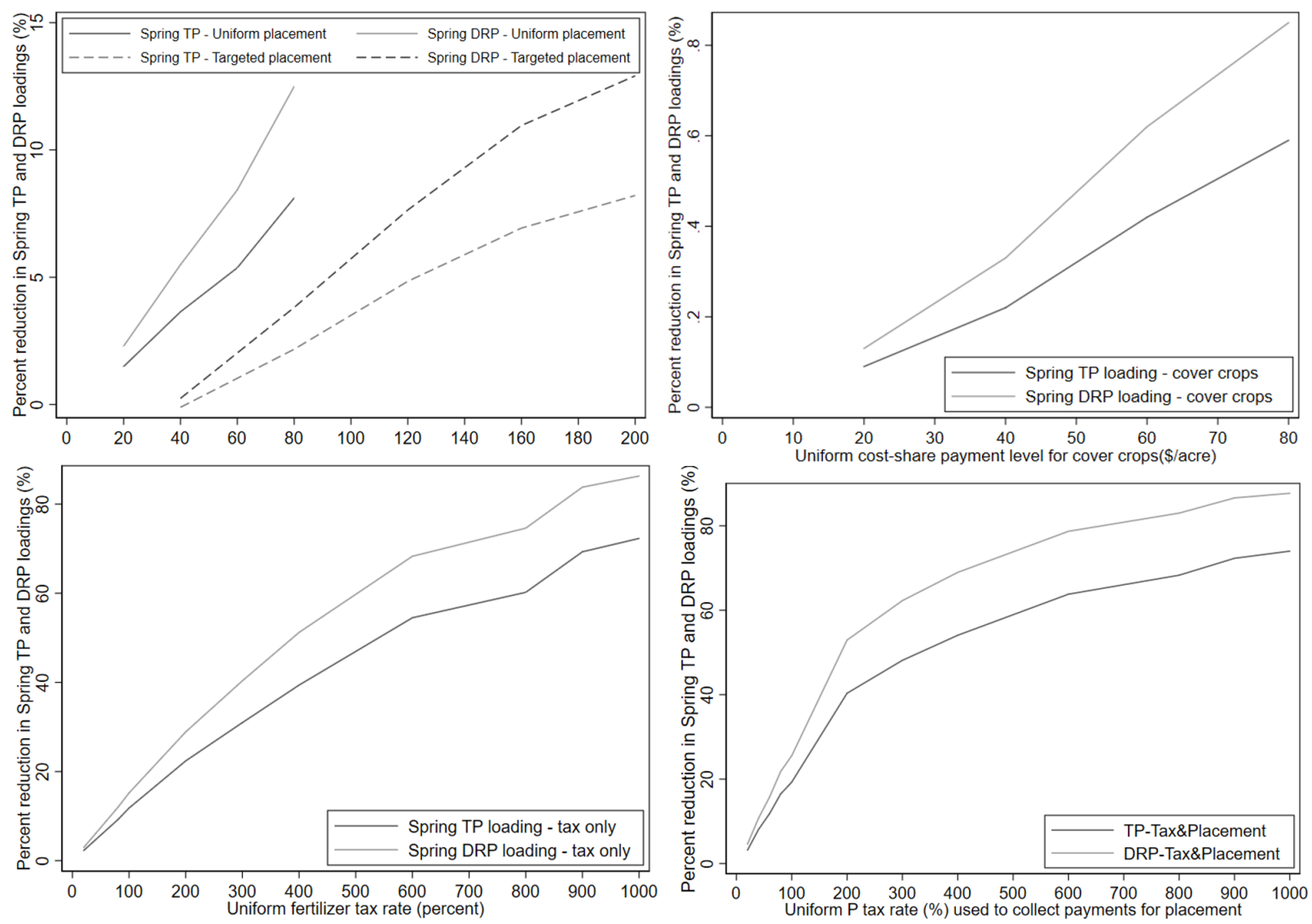
Figure 4. Tradeoff frontier of TP and DRP loading reductions versus policy costs under different nutrient management policies.
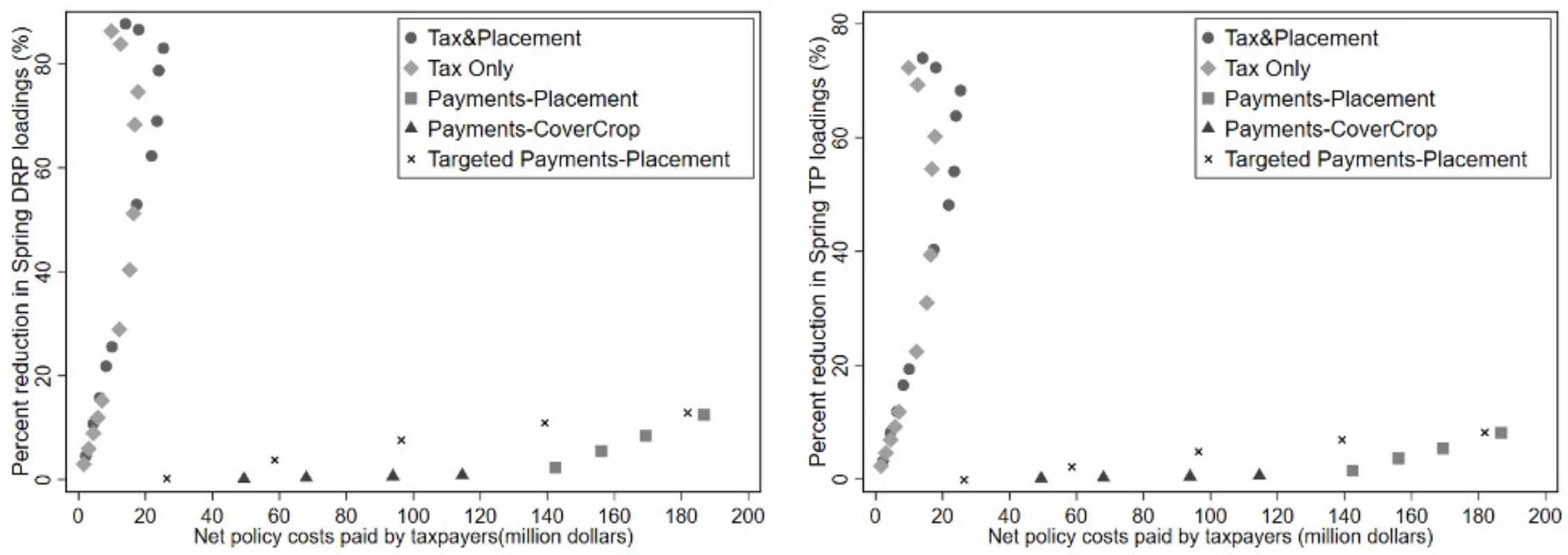


\section{Grouped Endnotes}

'Based on results from previous literature, we assume that policy costs are a function of program size. Specifically the costs of implementing the fertilizer tax are set at $7 \%$ of the total tax revenues generated ( $\$ 14$ million in the case of a $400 \%$ tax) and $10 \%$ for implementing the hybrid policy ( $\$ 17$ million in the case of a $200 \%$ tax). The latter is due to the added coordination that is necessary for redistributing the cost-share payments.

ii While this may suggest that our sample is not statistically representative of all 18,116 farms in the Maumee River watershed, the 2012 Census of Agriculture data also shows that over $80 \%$ of all cropland in Ohio and Indiana are located on farms with at least 180 acres and over half of the acreage is on farms with at least 500 acres (U.S. Department of Agriculture 2014). As larger farms manage a greater relative proportion of cultivated lands in the Corn Belt, they also have a disproportionate potential to impact environmental quality through adoption or non-adoption of conservation practices. In fact, in the western Lake Erie basin, almost $65 \%$ of the cropland is managed by farmers with operations of at least 500 acres, while those with operations under 50 acres manage less than 3\% of the total acreage (U.S. Department of Agriculture 2014). Since the focus of our article is farmers' water-quality-related management choices, it seems appropriate to focus on the larger farms, or the farmers who manage proportionally more acreage in the watershed, which is more important from both a behavioral and a water quality control perspective (Zhang et al. 2016).

iii Adams (IN), De Kalb (IN), Fulton (OH), Henry (OH), Hillsdale (MI), Paulding (OH), Putnam $(\mathrm{OH})$, Van Wert $(\mathrm{OH})$, and Williams $(\mathrm{OH})$. 
iv Please see Zhang (2015) for an example for a more comprehensive analysis of the policy costs for uniform and spatially targeted fertilizer tax policies, including changes in farmers' profitability.

${ }^{v}$ Policy baselines are different from the survey baselines because of uncertainties in future adoption decisions.

vi 2000-2004 period was used as both the model validation period as well as the model "spin up" time. We ran SWAT models from 2000 to 2015 but skip reporting results for the first five years of this period. We also used the period 2000-2004 in the validation process to calibrate the model.

vii Although not a focus of this paper, the SWAT model showed cover crops had a greater impact on nitrogen losses ( $3 \%$ as adoption rate increased from $20 \%$ to $63 \%$ ) than phosphorus losses $(<1 \%)$. However, these losses are below levels found in other studies (Ruffatti et al., 2019; Thapa et al., 2018).The factors described above could also contribute to the muted effectiveness of cover crops on nitrogen loss reductions in this SWAT model.

viii Although first-best policies can be efficient in theory, in reality they can be prohibitively expensive to implement (Lankoski et al. 2010) and most policies are second-best because of their uniform payments, transaction costs, information rent, or uncoordinated correction of policies (Claassen and Horan 2000; Larson, Helfand, and House 1996; Peterson et al. 2014; Weinberg and Kling 1996). 
Best Management Practices and Nutrient Reduction:

An Integrated Economic-Hydrological Model of the Lake Erie Basin

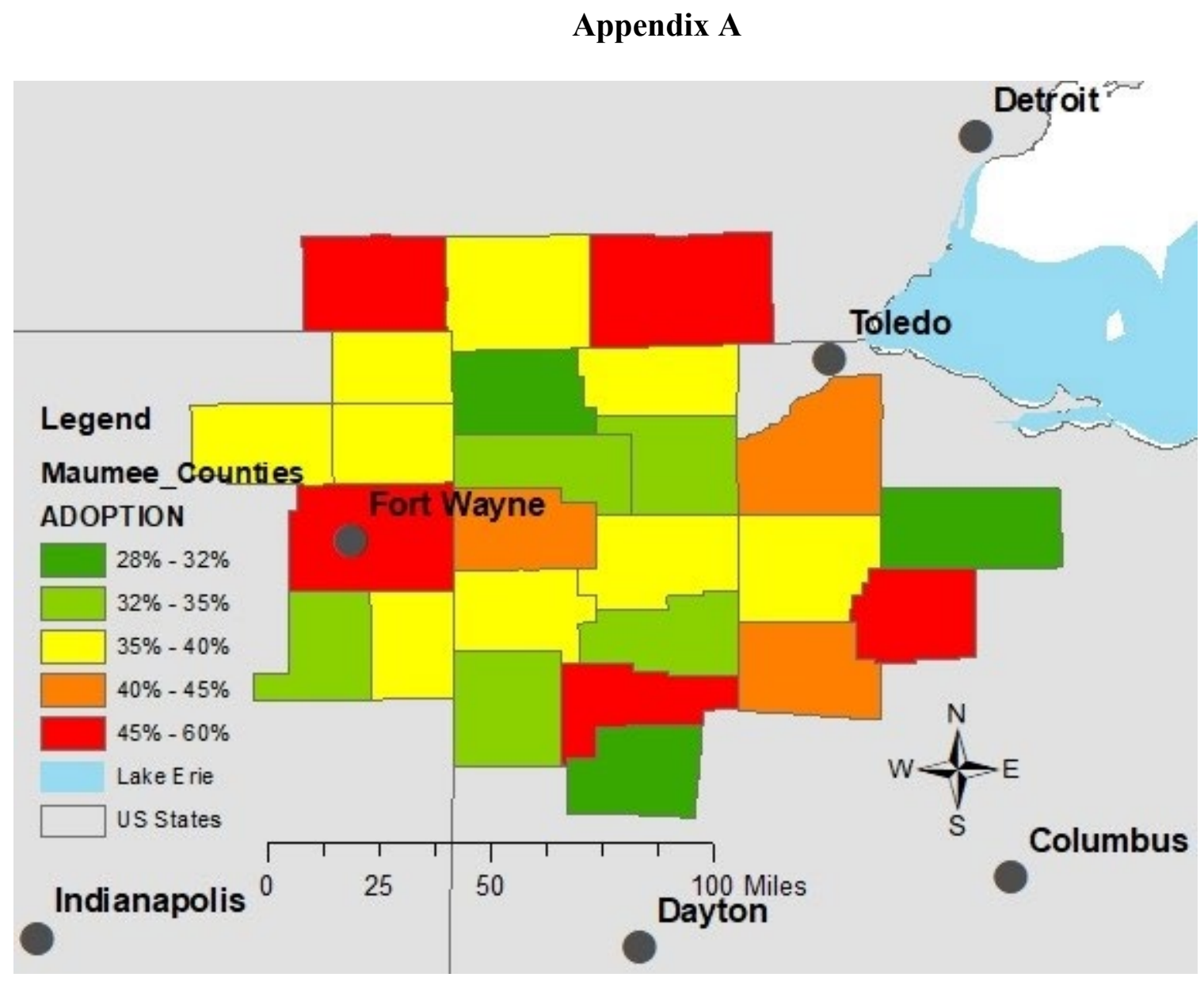

Figure A. Map of subsurface placement adoption based on the survey 


\section{Appendix B. Sample questions from the farmer survey regarding management costs}

- What plant population did you plant on this field for this most recent crop?

Quantity:

Price: seeds/acre

- Did you apply manure on this field for this most recent crop?

$\square$ No

$\square$ Yes $\rightarrow$ source of manure (check all that apply)

$\square$ Dairy $\square$ Swine $\square$ Poultry

Quantity: lbs/acre

Price: $\$ / \mathrm{lb}$

- Considering all fertilizers on this field for this most recent crop, how much phosphorus and nitrogen was applied and what was the price you paid? (Please write '0' if none was applied)

Rate (lbs/acre):

Price (\$/ton):

Form $(\mathrm{P})$ : Phosphorus Nitrogen

Form (N): $\square$ Urea $\square$ UAN $\square$ NH3

- How much in total did you spend on herbicide, insecticide, and fungicide for this field last year? Please select the costs per acre that best approximate your situation with this field.

$\square \$ 10 \square \$ 15 \square \$ 20 \square \$ 30$

$\square \$ 40 \square \$ 50 \square \$ 60 \square \$ 80$

- Is this field covered by any Federal Crop Insurance program?

$\square$ No $\quad \square$ Yes

- Do you rent this field?

$\square$ No

$\square$ Yes $\rightarrow$ Who is primarily responsible for nutrient management decisions? (Check one)

$\square$ Me alone

$\square$ Primarily me, with landlord input

Equally me and my landlord

$\square$ Primarily my landlord, with my input

$\square$ My landlord alone

Other

$\rightarrow$ What is your rental agreement with your landlord? (Check all that apply)

$\square$ Rent for cash 


\section{$\square$ Rent for a share of crop}

- Tell us more about the machinery and equipment you used on this field last year:

Horsepower of your largest tractor

Horsepower of combine harvester

Number of rows in planter

For more details, please refer to the descriptive report about the survey on this project website: http://ohioseagrant.osu.edu/archive/maumeebay/project/resources/ (Burnett et al. 2015). 


\section{Appendix C. Construction and prediction of field-level BMP adoption costs}

\section{C.1 Construction of Field-level Production Cost}

We calculate the total costs of managing the farm for each respondent based on their specific responses in the survey. In particular, each farmer was asked to allocate all their fields into high-, medium-, and low-productivity categories based on corn and soybean yield ranges and pick one field from a randomly selected quality class (e.g., pick one field among all high-productivity fields that they operate). For each chosen field, the farmer provided various field-specific expenditures that we used to construct the field-level production cost (see Appendix A for sample questions on these expenditures). These responses include field-specific seeding rate and seeding cost, manure quantity, type, and unit price, fertilizer application quantity, type, and unit price, per-acre expenditures on herbicide and federal crop insurance program, as well as whether the fields are cash rented from other farmers. The respondents also provided agricultural production details on corn drying, machinery usage and repairs, fuel usage, and labor and management conditions, which were converted into dollar-based expenditures using the statewide custom rates and standard production costs based on the 2012 Ohio State University Production Cost and Custom Rate Survey (Ward 2012).

\section{C.2 Predicting Field-level Adoption Cost of Conversation Practice}

Field-level adoption cost of specific conservation practices is one unique explanatory variable. For each practice - fertilizer subsurface placement or cover crops - we run a separate OLS regression of the field-level total production cost on field-level physical characteristics (e.g., field size, soil quality, rent status), management practice decisions (e.g., BMP adoption), and 
field operator's demographic characteristics (e.g., age). This regression allows us to separate the adoption cost for each conservation practice from its total production cost at the field level and allow for heterogeneity in this cost across fields and operators. We include two interaction terms between this adoption dummy—one operator demographic characteristic (age) and one fieldlevel characteristic — proxied by field size. Previous literature has demonstrated that adoption cost will vary by both operator and field characteristics (Traoré, Landry, and Amara 1998; Prokopy et al. 2008). We use the age of the operator and field size as two proxies for this heterogeneity. We represent the field size in both acreage and acreage bins and find robust results. ${ }^{i}$ In particular, we estimate two regressions for phosphorus fertilizer subsurface placement and cover crop adoption separately:

Field level total production cost

$$
\begin{aligned}
& =\alpha * \mathrm{X}_{\mathrm{field}}+\beta * \mathrm{X}_{\mathrm{operator}}+\gamma_{1} * \text { already adopted subsurface placement }+\gamma_{2} \\
& * \text { already adopted subsurface placement } * \text { age }+\gamma_{3} * \text { already adopted subsurface placement } \\
& * \text { acreage }+\gamma_{4} * \text { adopted any BMP other than subsurface placement } \\
& +\varepsilon \quad \text { Eq. [C1] }
\end{aligned}
$$

Field level total production cost

$$
=\zeta * X_{\text {field }}+\eta * X_{\text {operator }}+\theta_{1} * \text { already adopted cover crops }+\theta_{2}
$$$$
* \text { already adopted cover crops } * \text { age }+\theta_{3} * \text { already adopted covercrops } * \text { acreage }+\theta_{4}
$$$$
* \text { adopted any BMP other than cover crops }+\varepsilon
$$

where $\mathrm{X}_{\text {field }}$ includes field size, soil quality, whether the field is rented $(0 / 1)$, and whether the field has adopted any BMP other than subsurface placement (0/1); and, $\mathrm{X}_{\text {operator }}$ includes the age of the farmer. In particular, as explained earlier, we included a binary variable "already adopted," which equals one when the farmer has already adopted the BMP of interest on this specific field. 
We also control for the adoption of BMPs other than the one of interest including grid soil sampling with variable rate, delaying broadcasting when the forecast predicts a $50 \%$ or more chance of at least one inch of total rainfall in the next 12 hours, managing field water levels with drainage management systems, avoiding winter or frozen ground surface application of phosphorus, avoiding fall application of phosphorus, determining rates based on regular soil testing once within the rotation (or every three years), following soil test trends to maintain the agronomic range for phosphorus in the soil (15 to $30 \mathrm{ppm})$, and requiring a $4 \mathrm{R}$ certification program for private applicators.

In practice, the adoption dummy variable and these two interaction variables allow us to derive field-specific adoption costs after estimating these two aforementioned regressions: Field level predicted adoption cost for field i for subsurface placement $=\widehat{\gamma}_{1} *$ already adopted subsurface placement $+\widehat{\gamma_{2}} *$ already adopted subsurface placement $*$ age_i + $\widehat{\gamma_{3}} *$ already adopted subsurface placement $*$ field size_i Eq. [C3]

Field level predicted adoption cost for field i for cover crops $=\widehat{\theta_{1}} *$ already adopted cover crops $+\widehat{\theta_{2}} *$ already adopted cover crops $* \operatorname{age}_{\mathrm{i}}+\widehat{\theta}_{3} *$ already adopted cover crops $*$ field size $\mathrm{i}_{\mathrm{i}}$ Eq. [C4] where $\widehat{\gamma_{0}}, \widehat{\gamma_{1}}, \widehat{\gamma_{2}}, \widehat{\gamma_{3}}, \widehat{\theta_{0}}, \widehat{\theta_{1}}, \widehat{\theta_{2}}$, and $\widehat{\theta_{3}}$ are coefficients estimated from Eq. [C1] and Eq. [C2]. These regressions naturally suggest that in our study, the adoption costs for BMPs vary not only by the intrinsic features of BMP adoption $\left(\widehat{\gamma_{0}}, \widehat{\gamma_{1}}, \widehat{\theta_{0}}\right.$, and $\left.\widehat{\theta_{1}}\right)$, but also vary across different fields and farmers due to heterogeneous age/experience and spatially-varying field 
characteristics. We expect $\widehat{\gamma_{1}}$ and $\widehat{\theta_{1}}$ to be postitive, representing an increase in production cost in general due to BMP adoption, but $\widehat{\gamma_{2}}$ and $\widehat{\theta_{2}}$ to be negative meaning that more experienced operators could adopt these practices in a marginally more cost-effective manner. $\widehat{\gamma_{3}}$ and $\widehat{\theta_{3}}$ can be positive or negative depending on the particular BMP because some larger fields have lower per acre costs due to economies of scale, while some other larger fields require different technology or crops that potentially increase per acre costs.

\section{C.3 Predicting Field-level Adoption Cost of Conversation Practice}

We estimate Eq. [C1] to predict field-level adoption costs of subsurface placement. Table B.1 shows that on average the cost of adopting any BMP other than subsurface placement is $\$ 24$ per acre. Larger farms and better soil quality induce higher production cost, which may be interpreted as higher investment on the farm. Rented land also incurs higher associated costs. Our approach allows us to dissect the farm-specific adoption cost of BMP based on farmer demographic characteristics (represented by farmer's age) and farm-level physical characteristics (represented by field size). As predicted, we find $\widehat{\gamma_{1}}$ to be positive, showing there is additional cost of adopting subsurface placement. $\widehat{\gamma_{2}}$ and $\widehat{\gamma_{3}}$ are both negative, indicating that farmer experience and economy of scale reduces the per acre adoption cost. For those who adopted subsurface placement, the adoption cost decreases by $\$ 1$ per acre $\left(\widehat{\gamma_{2}}\right)$ with a one-year increase in farmer's age; and, a one-acre increase in field size decreases the adoption costs by about $\$ .28$ $\left(\widehat{\gamma_{3}}\right)$. Based on these estimates, we uncover the field- and farmer-specific subsurface placement adoption cost following Eq. [C3]: 
subsuface placement adoption cost

$$
=102.3464-1.0503 * \text { age }-0.2828 * \text { field acreage } \quad E q .[C 5]
$$

We set the lower bound of adoption cost at zero and replace those below zero with zero because it is unrealistic to assume a negative adoption cost, which accounts for less than the lowest $5 \%$ tail of the distribution. The average estimated per acre subsurface placement adoption cost is $\$ 24.32$ based on average farmer characteristics and field-level characteristics, which is in line with BMP adoption cost, and different federal or state cost-share programs. Generally, subsurface placement is $\$ 12-\$ 15$ more per acre than broadcast phosphorus application, where broadcasting costs $\$ 4.10-\$ 15.20$ per acre depending on the fertilizer type. For non-adopters, we assume their costs are higher and use the 75 th percentile $(\$ 100.07 /$ acre $)$ of the adoption cost distribution as the proxy.

Table C.1. Subsurface Placement Adoption Cost Estimates

\begin{tabular}{lll}
\hline Variable & \multicolumn{2}{c}{ Total cost } \\
\cline { 2 - 3 } & Field acreage & Field acreage bins \\
\hline Other_BMP & $23.7767^{* * * *}$ & $25.6974^{* * *}$ \\
Field_acre & $(7.228)$ & $(7.253)$ \\
& $0.2821^{* * *}$ & \\
Field_size_bin_dummy & $(0.058)$ & \\
& & $32.3665^{* *}$ \\
Age & & $(12.677)$ \\
& -0.2244 & -0.2329 \\
Soil_quality & $(0.212)$ & $(0.213)$ \\
& $27.6678^{* * *}$ & $28.4730^{* * *}$ \\
Field_rent & $(3.446)$ & $(3.460)$ \\
& $14.1109^{* * *}$ & $14.4501^{* *}$ \\
Already_placement $\left(\widehat{\gamma_{0}}\right)$ & $(6.013)$ & $(6.039)$ \\
& $102.3464^{* * *}$ & $127.7725^{* * *}$ \\
Already_placement*age $\left(\widehat{\gamma_{1}}\right)$ & $(26.584)$ & $(33.620)$ \\
& $-1.0503^{* *}$ & $-1.0638^{* *}$ \\
Already_placement*field acreage $\left(\widehat{\gamma_{2}}\right)$ & $(0.440)$ & $(0.442)$
\end{tabular}


Already_placement* Field_size_bin_dummy $\left(\widehat{\gamma_{2}}\right)$

Constant

Fixed effect

Observations
-37.0227 *

(20.424)

$218.3774 * * *$

(64.200)

County level

2,324

The results for cover crops resemble that for subsurface placement (Table B.2), and similarly, wee uncover the field- and farmer-specific cover crop adoption cost following Eq. [C4]:

cover crop adoption cost $=38.8825-1.0555 *$ age $+0.2957 *$ field acreage $\quad$ Eq. [C6]

As expected, we find $\widehat{\theta_{1}}$ to be positive, showing the additional cost of adopting cover crops. We find $\widehat{\theta_{2}}$ to be negative, indicating one year of experience reduces the adoption costs by about $\$ 1$. Here we find adoption cost increases with field size, which could be explained by the different types of cover crops or different technology chosen due to the field size. Using these proxies, we find that the average per acre adoption cost for cover crops is $\$ 31.70$, which is in the range of USDA-NRCS payments (\$28.71/acre to \$34.76/acre). ${ }^{\text {ii }}$ Again, for non-adopters, we assume their costs are higher and use the 75 th percentile $(\$ 36.60 /$ acre $)$ as a proxy for their adoption costs.

Table C.2. Cover Crops Adoption Cost Estimates

\begin{tabular}{lll}
\hline \hline Variable & \multicolumn{2}{c}{ Total cost } \\
\cline { 2 - 3 } & Farm acreage & Farm acreage bins \\
\hline Other_BMP & $38.3383^{* * *}$ & $38.4771^{* * *}$ \\
Field_acre & () & $(6.87)$ \\
Field_size_bin_dummy & -0.0007 & \\
Age & $(.002)$ & $21.3790^{*}$ \\
& & -11.072 \\
& & $-0.3396^{*}$
\end{tabular}


Soil_quality

Field_rent

Already_cover_crop $\left(\widehat{\theta_{0}}\right)$

Already_cover_crop*age $\left(\widehat{\theta_{1}}\right)$

Already_cover_crop*acreage $\left(\widehat{\theta_{2}}\right)$

Already_cover_crop* Field_size_bin_dummy

Constant

Fixed effect

Observations
$(0.198)$

$27.5982 * * *$

(3.488)

$13.6962 * *$

(6.077)

38.8825

(36.938)

$-1.0555^{*}$

$-0.614$

$0.2957 * *$

$-0.13$

$272.0461 * * *$

$-61.978$

County level

2,324
$-14.4433$

$-44.877$

(0.198)

$27.9594 * * *$

(3.486)

$13.7392 * *$

(6.083)

73.2262

(44.877)

$-1.1383^{*}$

$-0.613$

$246.7916^{* * *}$

$-63.363$

County level 


\section{Appendix D. Combinations of tax and cost-share payments}

Table D. Combinations of tax and cost-share payments

\begin{tabular}{ccc}
\hline Tax $(\%)$ & $\begin{array}{c}\text { Total revenue } \\
\text { (million dollars) }\end{array}$ & $\begin{array}{c}\text { Matching payment for } \\
\text { subsurface placement } \\
\text { (\$/acre) }\end{array}$ \\
\hline 20 & 22.30 & 10 \\
40 & 43.42 & 20 \\
60 & 63.35 & 30 \\
80 & 82.10 & 40 \\
100 & 99.66 & 45 \\
200 & 173.57 & 170 \\
300 & 218.00 & 200 \\
400 & 234.21 & 210 \\
\hline
\end{tabular}

For each level of tax revenue, we find the most efficient way of using it as cost-share payment, i.e. the level that leads to highest adoption rate. For example, the $20 \%$ fertilizer tax will collect \$22.3 million dollars, if used for payment for subsurface placement, it can pay \$10/acre which leads to $50.25 \%$ of adoption. Note that this adoption rate is lower than current adoption rate without policy intervention, which is because we use the Lewis and Plantinga (2007) method take into account of the uncertainty in future adoption, even for current adopters. Similarly, if budget is used for cover crops payment, it can pay $\$ 25 /$ acre which leads to about $30.65 \%$ of adoption. Note that the current adoption rate is lower for cover crops, which requires higher payment to increase.

In Figure D, we plot the percent changes in loadings as a function of the fertilizer tax across a wide range of tax rates to investigate the tax rate that minimizes loadings in both the taxonly and hybrid policy cases, according to Equation [4] and as described in section 3.2.3, which forces us to consider unrealistic levels of a fertilizer tax. We find that total tax revenues are 
maximized at about an $800 \%$ tax, and that the tax rate at which loadings are minimized in both the tax-only and hybrid tax scenarios is closer to $1000 \%$ percent. At a $1000 \%$ tax, the model predicts that the average fertilizer application is driven to 0 , which makes this tax a "choke price." The result is a corner solution: the effectiveness of reduced fertilizer application in reducing loadings dominates the effectiveness of either BMP in reducing loadings, and therefore the most effective approach to reducing loadings is simply to reduce fertilizer application.

Clearly these are highly unrealistic scenarios, and we include them only for illustrative purposes to examine the relative differences in the policies and the potential trade-off in loading reductions from the hybrid policy. As explained in section 3.2.3, this approach omits a broader consideration of cost and benefits, included the foregone profits from massive increases in fertilizer costs that drive application rates to zero. The optimal tax would account for these forgone profits while also considering the social benefits of reduced loadings in terms of improved ecosystem services. Both effects are likely to be substantial, and thus a full analysis of the optimal tax policy is important, but beyond the scope of this paper.
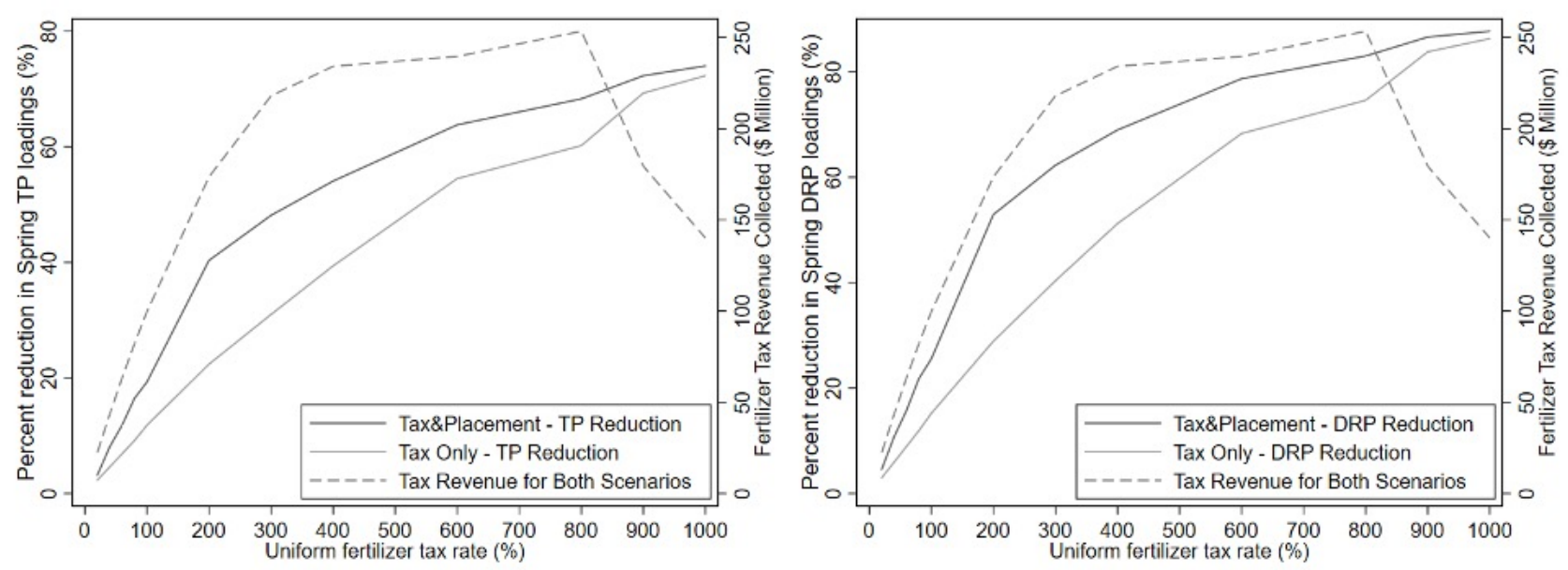

Figure D. Comparison of TP and DRP reduction of tax policies 
Appendix E.
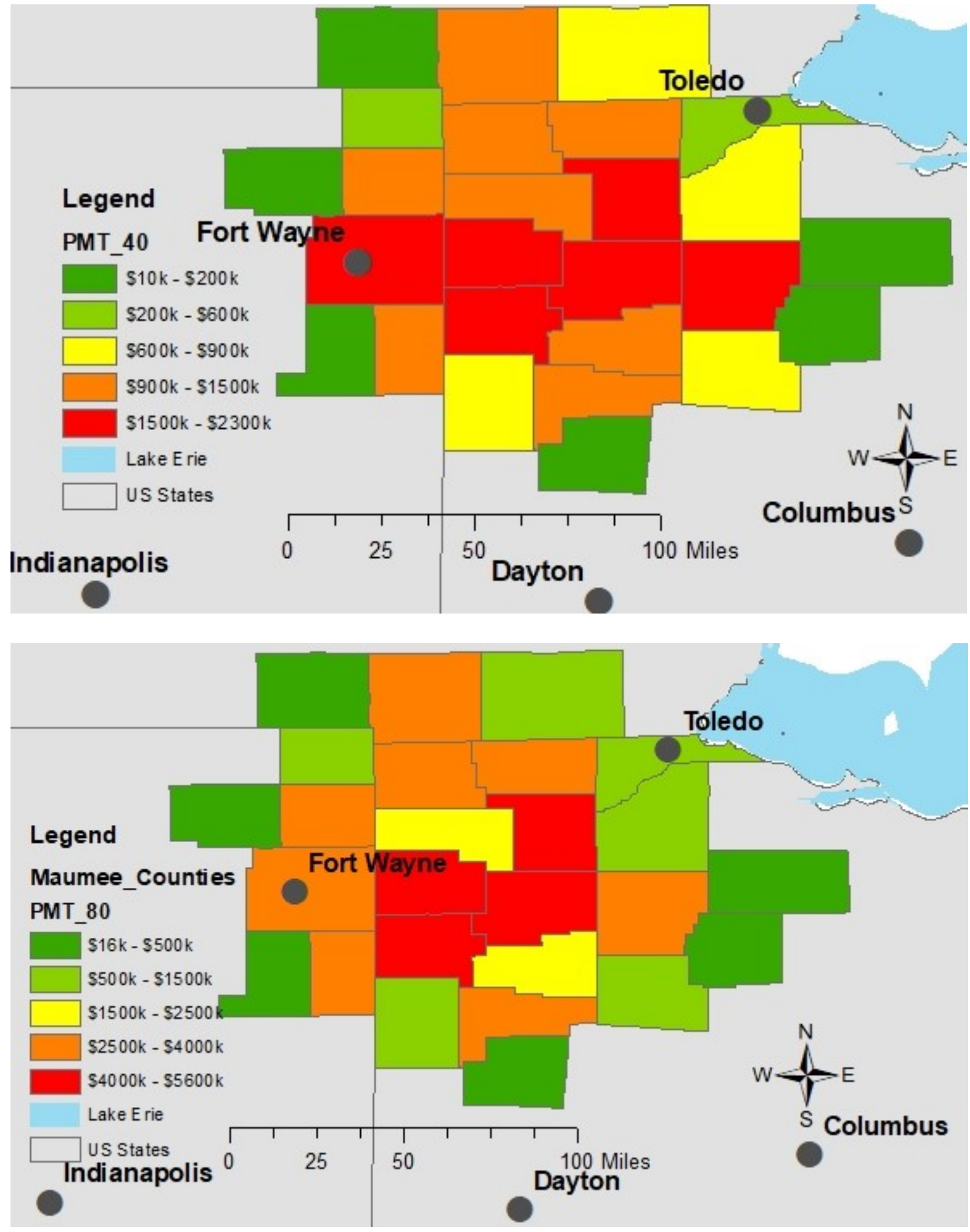


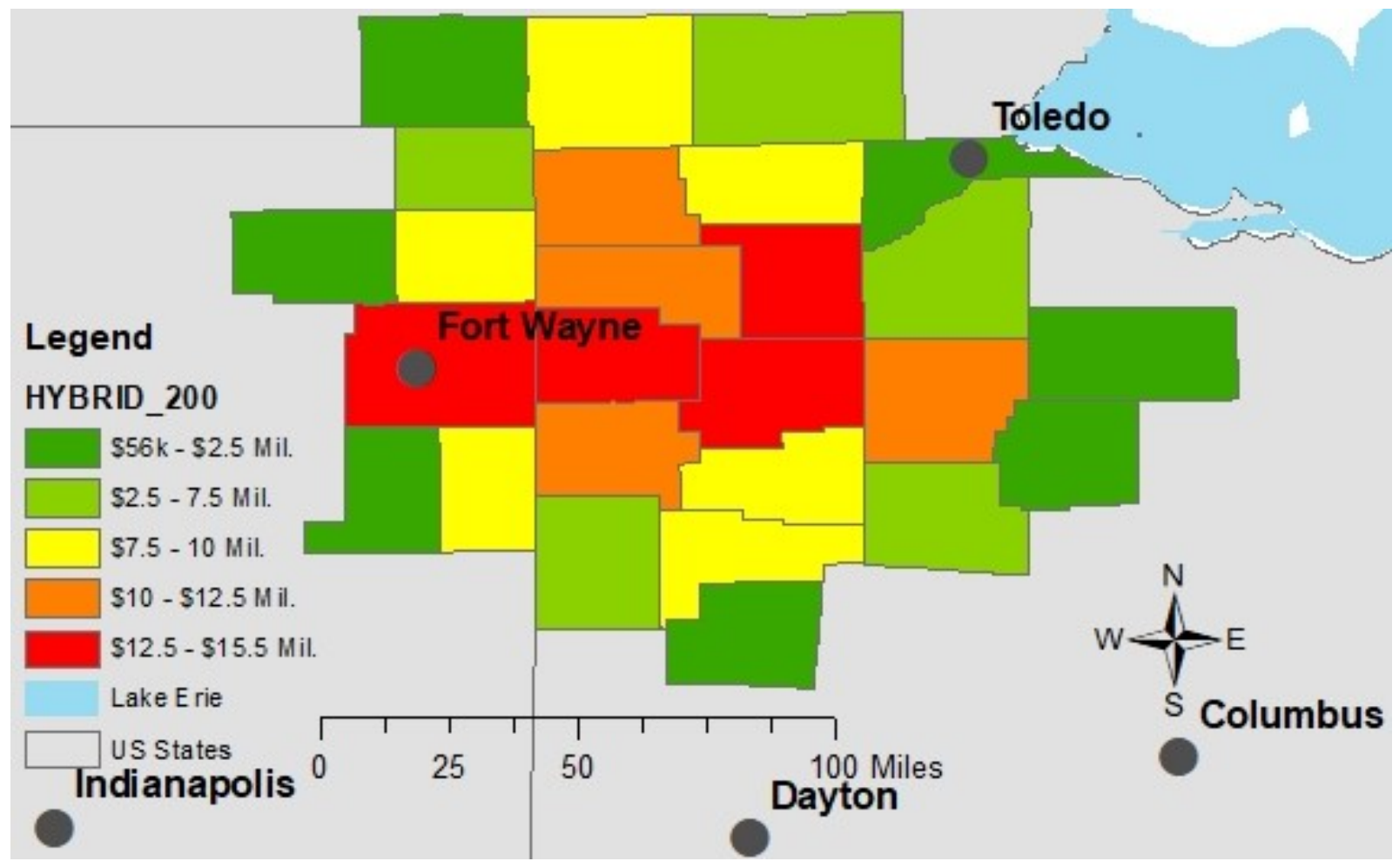

Figure E. Policy costs and tax burden for: (a) \$40/acre uniform payment, (b) \$80/acre spatially targeted payment, (c) $200 \%$ tax+payment hybrid policy. 


\section{Grouped Endnotes}

${ }^{\text {i }} 150$ acres each bin
${ }^{\text {ii }} \underline{\text { https://www.nrcs.usda.gov/Internet/FSE_DOCUMENTS/stelprdb1082778.pdf }}$ 